\title{
The Effect of Coupled Mass Transport and Internal Reforming on Modeling of Solid Oxide Fuel Cells Part I: Channel-Level Model Development and Steady-State Comparison
}

\author{
K. J. Albrecht, R. J. Braun* \\ Department of Mechanical Engineering, College of Engineering and Computational Sciences, Colorado \\ School of Mines, 1610 Illinois Street, Golden, CO 80401, USA
}

\begin{abstract}
Dynamic modeling and analysis of solid oxide fuel cell systems can provide insight towards meeting transient response application requirements and enabling an expansion of the operating envelope of these high temperature systems. SOFC modeling for system studies are accomplished with channel-level interface charge transfer models, which implement dynamic conservation equations coupled with additional submodels to capture the porous media mass transport and electrochemistry of the cell. Many of these models may contain simplifications in order to decouple the mass transport, fuel reforming, and electrochemical processes enabling the use of a 1-D model. The reforming reactions distort concentration profiles of the species within the anode, where hydrogen concentration at the triple-phase boundary maybe higher or lower than that of the channel altering the local Nernst potential and exchange current density. In part one of this paper series, the modeling equations for the 1-D and 'quasi' 2-D models are presented, and verified against button cell electrochemical and channel-level reforming data. Steady-state channel-level modeling results indicate a 'quasi' 2-D SOFC model predicts a more uniform temperature distribution where differences in the peak
\end{abstract}

\footnotetext{
${ }^{*}$ Corresponding author. Tel.: + 303273 3055; fax: + 3032733602.

Email addresses: kalbrech@mymail .mines . edu (K. J. Albrecht), rbraun@mines .edu (R. J. Braun
} )

Preprint submitted to Elsevier

October 30, 2015

(C) 2015. This manuscript version is made available under the Elsevier user license http://www.elsevier.com/open-access/userlicense/1.0/ 
cell temperature and maximum temperature gradient are experienced. The differences are most prominent for counter-flow cell with high levels of internal reforming. The transient modeling comparison is discussed in part two of this paper series.

Keywords: Steady-State, SOFC, Modeling, Mass Transfer, Dusty Gas Model, Internal Reforming

\section{Introduction}

The high electrical efficiency ( $>50 \%$ ), fuel flexibility (natural gas, biogas, syngas, etc.), and high quality waste heat $\left(>350^{\circ} \mathrm{C}\right)$ have made solid oxide fuel cells (SOFCs) a key area of industrial development and academic research interest over the past decade or so. Should cost targets and market barriers be reduced, these benefits suggest that SOFCs are likely to represent a significant component of the future distributed generation technology mix. However, dynamic operation and dispatch of power generation systems is often required for both stationary and mobile applications. The attractiveness of SOFC-based distributed power systems will further be enhanced by an expansion of the dynamic operating envelope to accommodate load-following strategies and utility dispatch requirements. At present, degradation effects can severely limit the operational lifetime of planar SOFCs. Dynamic modeling tools can assist in determining when harmful operational conditions may be encountered and are crucial to accelerating technology readiness. Although the focus of this paper is not on quantifying degradation effects, they are considered when assessing the accurate and representative model-predictive cell performance.

Motivation for the present work stems from several considerations. It is commonly acknowledged that dynamic operation of SOFC's is to be avoided. However, recent research has suggested that degradation phenomena could be reduced resulting in longer operational lifetimes through dynamic operation of SOFCs, provided that operating conditions can be maintained throughout load changes [40]. Thus, a useful objective is the development of physically based computationally efficient dynamic models, where 
all of the relevant physical phenomena are captured while not appreciably adding to the complexity of the model. Such tools can support controls development and provide system-level supervisory control set points. Additional research has been conducted on the dynamic dispatch and design of distributed generation SOFC systems using mixed integer, non-linear programing where models capturing off-design characteristics are compared to base-loaded steady-state models [47]. The study concludes that in certain cases optimal dynamic dispatch of SOFCs will be dependent on accurately capturing the system transients, neglecting these dynamics could lead to a significantly undersized system. Finally, research has been conducted on the effects of the operational strategy of SOFCs on the combined heat and power efficiency and cost of electricity, where a dynamic grid-support operation yielded the highest combined heat and power efficiencies and lowest cost of electricity [43]. These studies give rise to the demand for higher fidelity physically based models, which are still computationally efficient for integration into system-level models.

Over the past years there have been numerous modeling efforts of dynamic SOFCs with system-level simulations in mind [4, 2, 5, 12, 20, 25, 39, 48, 49, 50, 26], including both lumped and spatially resolved models. Typically, these models include numerous simplifications of the physical processes occurring in the cell such as internal reforming, mass transport, and electrochemical kinetics. The reason behind the simplification is to decouple the effects of electrochemistry and internal reforming, leading to a more computationally efficient model, where the cell is approximated as lumped or over a single dimension. However, neglecting the coupled effects could influence cell behavior and operational envelopes. In particular, correctly predicting local fuel starvation in an effort to avoid destructive nickel oxidation of the anode electrode during dynamic load change is important to understanding both the SOFC operating envelope and the needed modeling approach to accurately capture those physics.

The objective of this paper is to establish cell model fidelity requirements for 
steady-state simulation of internally reforming SOFC systems - the system type most likely to be found in distributed generation applications. The present work thus presents the development of dynamic modeling equations for channel-level interface charge transfer cell models and provides a steady-state comparison between a typical 1-D and a 'quasi' 2-D channel-level model. The comparison of transient model results is presented in part two of this paper series [? ]. The resulting computational tool is intended to support system-level simulation where the channel could be extrapolated into a stack with further work and implemented alongside other dynamic BOP component models.

\subsection{SOFC Fundamentals}

SOFCs are energy conversion devices, where a gaseous fuel is converted into DC power through electrochemical oxidation. Many complex physical phenomena occur in the operation of SOFCs including, charge transport, heterogeneous chemistry, porous media mass transport, heat transport and viscous flow. Figure 1 displays a graphical representation of a single cell in a planar SOFC configuration. The operation of an SOFC can be described by the two half-cell reactions where hydrogen is oxidized at the anode triple phase boundary (TPB) and oxygen is reduced at the cathode TPB, equations (1) and (2) respectively.

$$
\begin{gathered}
\mathrm{H}_{2}+\mathrm{O}^{2-} \rightleftharpoons \mathrm{H}_{2} \mathrm{O}+2 \mathrm{e}^{-} \\
\frac{1}{2} \mathrm{O}_{2}+2 \mathrm{e}^{-} \rightleftharpoons \mathrm{O}^{2-}
\end{gathered}
$$

In its simplest representation, a fuel cell can be fueled with hydrogen and oxygen gases that are separated by the PEN (Positive electrodelElectrolytelNegative electrode) structure. Actual SOFCs are more complicated. For example, an anode-supported cell consists of a cathode, electrolyte, anode functional and support layers, and current collection. The electrolyte is typically constructed from yttria stabilized zirconia 
(YSZ), which allows for oxygen ion transport at high temperatures but not electron transport. The anode and cathode functional layers are mixed electronic and ionic conductors (MEIC), where the electrochemical oxidation and reduction of species occurs, via charge transfer reactions, along the length of the three phase boundary TPB. For the reactions to propagate the electrode, electrolyte, and gas phases must all be in contact in the anode or cathode. MEIC electrodes consist of particles which will be in the electrode phase and particles in the electrolyte phase, with the purpose of increasing the length of the TPB and electrochemical activity of the cell. Typically, the anode is constructed from a Ni-YSZ cermet, and the cathode can be constructed from lanthanum strontium manganite (LSM) or lanthanum strontium cobalt ferrite (LSCF).

Electrochemistry and charge transport are regarded as the most difficult aspects of fuel cell modeling [18]. The equilibrium potential of a cell can be easily defined from the Nernst potential while at equilibrium conditions (i.e., zero current). However, once the cell departs from the equilibrium condition (current is positive) into typical operation, losses will begin to occur due to mass transport of the products and reactants from the bulk gas to the TPB, resistance to ion transport within the electrolyte, and increased potential differences between the electrode and electrolyte phases due to electrochemical reaction kinetics. The concentration losses occur due to the diffusion of species through the porous anode and cathode which leads to a reduced concentration of the electrochemical reactant species and an increase in the concentration of the electrochemical product species at the TPB. This effect tends to lower the cell voltage via an effective mass transport resistance. Electronic resistances are also present in the cell due to the finite conductivity of the PEN materials. The electrons produced and consumed by the half-cell reactions at the TPBs must be transported through the electrode phase of the anode and cathode to the current collector. By comparison the voltage overpotential associated with electronic resistance to current flow is typically small relative to the ion transport in the electrolyte. (However, when cells are stacked 
in electrical series the electronic contact resistance between repeat units can be substantial enough that the effective stack performance is not representative of single cell performance [24].)

The kinetics of the electrochemical reactions can be increased or decreased by changing the potential difference between the electrode and electrolyte phases at the TPB where the reaction will propagate. Through changing this potential difference the net activation energy that must be overcome is reduced, however, the potential between the two electrodes is also reduced. In other words, the electrochemical reaction rate will increase as cell potential is decreased.

The anode is divided into two distinct layers where the purpose of the functional layer is to maximize the length of the TPB increasing the electrochemical activity of the cell, and the support layer is for structural integrity. The presence of the nickel particles distributed through the anode support and functional layers is to (1) catalyze the methane steam reforming and water-gas-shift reactions, equations (3) and (4), respectively, and (2) to increase the electronic conductivity of the electrode.

$$
\begin{gathered}
\mathrm{CH}_{4}+\mathrm{H}_{2} \mathrm{O} \rightleftharpoons \mathrm{CO}+3 \mathrm{H}_{2} \\
\mathrm{CO}+\mathrm{H}_{2} \mathrm{O} \rightleftharpoons \mathrm{CO}_{2}+\mathrm{H}_{2}
\end{gathered}
$$

The heterogeneous reforming chemistry occurs on the nickel surface through the depth of the anode, where interactions between the reforming chemistry and mass transport may influence the electrochemical reactions at the TPB. Most channel-level models neglect the effect of reforming on the species concentration profiles throughout the anode depth, however, several dynamic models have been developed which begin to take this effect into account $[49,12]$. 


\section{Prior Channel-Level Modeling}

Many dynamic SOFC models have been developed to assess the effects of transient SOFC operation. This section will focus on published dynamic channel-level models which could be implemented into a system-level simulation, and steady-state models of coupled chemical reaction and mass transport.

One of the first dynamic SOFC modeling efforts was proposed by Achenbach [2] where a simplified '3-D' stack-level model was presented to assess the effects of flow configuration and step changes in current density on cell performance. Although this work provided one of the first fundamental frameworks for modeling of SOFCs, the authors acknowledged that the formulation of the electrochemical and methane steam reforming model equations should be taken as preliminary, and be updated as models which are more representative of the physical phenomena are developed. Even with this statement, many models have continued to use the methane steam reforming rate expression proposed by the authors [3], which is based on a nickel cermet with a nickel loading that is far below what is commonly observed in SOFC anodes.

Aguiar et al. [4] proposed a 1-D physically based model to represent a single channel of an SOFC. The model implemented the previously described steam reforming rate expression of Achenbach [3], and neglected the conservation of momentum with a constant velocity assumption. The development of this model resulted in a more descriptive yet still relatively simple electrochemical model which accounted for concentration, activation, and ohmic overpotentials. With the increased knowledge of the reforming process and detailed electrochemical kinetics, a more representative model of the electrochemistry and heterogeneous chemistry is still possible. Iora et al. [20] improved upon Aguiar's model implementing a dynamic momentum balance and position dependent physical properties, however, difference between Aguiar's model were shown to be relatively small.

More recent dynamic channel-level models developed by Chaisantikulat et al. [11] 
and Barzi et al. [8] have been formulated to resolve the concentration of species throughout the fuel and air channels based on bulk flow and diffusive mass transport. Both models only consider humidified hydrogen fuel compositions, however, the results indicated that under the operating conditions significant gradients in the electrochemically active species were not developed in the fuel channel transverse to the bulk flow. This numerical technique allows for the convective heat transfer to be accounted for by CFD rather than Nusselt number correlations. Barzi stated that 1-D models will over estimate the convective heat transfer coefficient leading to faster dynamics. However, the computational efforts of these models are expected to be high, where implementation in a system-level simulation would be difficult.

Physical representation of the coupled mass transport and chemical reaction dynamics was acknowledged through the modeling efforts of Colclasure et al. [12] and Qi et al. [48]. Colclasure's model represented the mass transport and chemical reaction as occurring in two anode discretizations of the functional and support layers, where Qi's model considered the dynamics of the mass transport being characterized in a transfer function of a state-space model. Although Colclasure's physically based model incorporated dynamic mass transport equations, the purpose was to validate a reduced-order model [50]. Modeling the reforming and transport with two discretizations could lead to reductions in the reforming rate, if two discretizations is an insufficient discretization scheme. The model developed by Qi showed that the mass transport dynamics occur on a time scale of less than one second, which is far less than the thermal time scale of an SOFC, which is on the order of $10^{3}$ seconds.

Many additional steady-state models have been developed to consider the modeling effects of the mass transport through the porous anode material and in many cases account for the coupled reaction kinetics. The work of Suwanwarangkul et al. [53] compared three mass transport models; Fick's model, Stephan-Maxwell Model, and Dusty Gas Model (DGM) for calculating anodic concentration overpotentials conclud- 
ing that the DGM is currently the most appropriate model for simulating gas transport in the porous anode. However, the work of Vural et al. [56] has disputed the claims of the accuracy of the DGM concluding that the predictions of the Stephan-Maxwell Model and Binary Friction Model are equally valid when tortuosity is taken as a fitting parameter and the pressure gradient term found in the DGM is of relatively low importance for SOFC modeling. The work of Ni et al. [44] showed that the pressure gradient established across the anode could significantly impact not only the concentration overpotential, but the rate of steam reforming and the depth at which it occurs. Most recently, Wang et al. [57] has challenged the appropriateness of the DGM citing improved models of the Cylindrical Pore Interpolation Model and Binary Friction Model, however, results displayed that when the pressure gradient term is considered predictions between the DGM and improved models are minimal. It is clear that many conflicting results have been produced, however, for the purpose of this modeling effort the DGM is considered for modeling anode mass transport because it has been consistently able to match experimental results $[13,56]$.

Additionally, a wide array of steady-state interface charge-transfer, channel-level models have been formulated to resolve the concentration of species throughout the depth of the anode $[63,22,61]$, many of these models rely on an elementary reaction mechanism [19] which is far too complicated for dynamic channel-level modeling where global rate expressions are preferred. Some of the models [7] have focused on combining submodels which have been formulated on the microscale and models which are derived for the macroscale so that important physics can be captured over many orders of magnitude. The authors conclude that these types of modeling procedures should be implemented more often, and always validated with experimental results.

Steady-state models have been developed which look to resolve the distribution of the electrochemical reactions through the depth of the anode and cathode functional 
layers, which are based on elementary reaction kinetics $[62,13]$. These models are based on either an assumption of the depth of the electrochemical reaction or on percolation models which extend the TPB throughout the depth of the functional layer. However, for the purpose of dynamic channel-level modeling, a simplification the distributed elementary charge transfer process (i.e., from a distributed to a single interface) is required for computational efficiency. Simple models have been developed which derive a modified form of the Butler-Volmer equation based on a rate limiting step assumption of the elementary transfer mechanism of both half-cell reactions [63]. The derivation shows that the anodic and cathodic exchange current densities are not only functions of temperatures, but the gas phase composition as well, which influences the surface coverages of adsorbed species. However, simplification of the model to a modified Butler-Volmer formulation requires the assumption that only a single fuel species (and charge transfer pathway) is able to participate in the electrochemical oxidation reaction. Although it has been demonstrated that SOFCs are able to electrochemically oxidize carbon monoxide [23], resolving the current-voltage characteristics of a mixed fuel source can only be fully addressed through elementary charge transport mechanisms.

One of the main objectives of the present work is to assess the importance of model fidelity as it pertains to electrode species transport and reaction during steady-state operation. Thus, we wish to establish the importance of detailed reaction and transport modeling (via resolving the anode electrode) on channel-level models whose purpose is implementation in stack and system-level simulation. The remainder of this paper will be focused on the mathematical development of the two separate modeling methodologies, model verification, and a steady-state comparison of the results. 


\section{Simple 1-D Physically Based Dynamic Modeling Methodology}

Mathematical models of SOFCs are developed through formulation of differential material and energy balances on fuel and air channels, and PEN and interconnect layers. The resulting system of partial differential equations are typically discretized in space and solved via a method of lines algorithm. In the simplified modeling methodology typically implemented for channel-level SOFC modeling, the assumptions for deriving the equations are as follow:

1. The depth of the reforming reaction on the anode support is negligible, and the heterogeneous chemistry can be approximated as occurring on the external anode surface.

2. Radiation between the PEN and interconnect is negligible, as well as the participation of the gas phase species

3. The pressure gradient developed across the anode from the porous media mass transport is negligible. The mass transport can be assumed to occur as equimolar counter diffusion at constant pressure.

4. Solid PEN temperatures are lumped and only resolved in the streamwise direction.

5. Fuel and air channels have fully developed laminar flow resulting in a constant Nusselt number.

6. Conduction and diffusion in the fuel and air channel gas phases in the streamwise direction can be neglected.

7. A static momentum balance is sufficient for capturing channel-level fluid dynamics at the time scale of interest.

8. Only hydrogen is oxidized at the TPB.

This modeling methodology was developed to simulate a single channel in a planar SOFC, where the boundaries are assumed to be identical cells in the stack. Although differences are known to exist between stack and repeated channel-level mod- 
els $[27,35,55,24]$, for example, where stack boundary conditions involve radiation and convection, increases in ohmic overpotential are present due to layer-to-layer contact resistance, and non-uniform flow distribution. The methodology considered here provides the necessary knowledge for the development of stack-level models.

\subsection{1-D Dynamic Material Balance Equations}

The material balance equations were derived for a single species in the fuel $(s f)$ or air channel ( $s a$ ), where the fuel is assumed to only contain the species $\mathrm{CH}_{4}, \mathrm{CO}_{2}, \mathrm{CO}$, $\mathrm{H}_{2} \mathrm{O}, \mathrm{H}_{2}$ and the air is assumed to be only a mixture of $\mathrm{N}_{2}$ and $\mathrm{O}_{2}$. For the derivation of the individual species balance equations, the dependent variables will be taken as the species concentrations. Although total moles are not conserved, the individual species balance is equivalent to a mass balance.

The dynamic species material balance for the fuel channel is derived from the fuel channel differential control volume displayed in Figure 2. The resulting differential equation involves terms representing the storage, bulk flow and chemical reactions. In the fuel channel the reactions considered are the hydrogen oxidation, methane steam reforming, and water-gas-shift ( $k \in \mathrm{ox}, \mathrm{sr}, \mathrm{wgs})$. The storage term is the time derivative of the species concentration $\left(C_{s f}\right)$, the bulk flow terms are the spatial derivative of the species concentration multiplied by the bulk fluid velocity $\left(U_{\mathrm{f}}\right)$, and the reaction term is the summation of the reaction rates $\left(r_{k}\right)$ multiplied by the stoichiometric coefficients $\left(v_{s f, k}\right)$.

$$
\underbrace{\frac{\partial C_{s f}}{\partial t}}_{\text {Species Concentration }}=-\underbrace{\frac{\partial C_{s f} U_{\mathrm{f}}}{\partial x}}_{\text {Bulk Flow }}+\underbrace{\frac{1}{t_{\mathrm{f}}} \sum_{k} v_{s f, k} r_{k}}_{\text {Reaction }}
$$

The dynamic species material balance in the air channel is derived in a similar manner, where the differential control volume is displayed in Figure 2. Since the only chemical reaction occurring in the air channel is the oxygen reduction $\left(r_{\mathrm{Ox}}=j / 4\right)$, the reaction term does not require a summation over multiple reactions. From the differential control volume it can be shown that the equation can be derived resulting in 
Equation (6).

$$
\underbrace{\frac{\partial C_{s a}}{\partial t}}_{\text {Species Concentration }}=-\underbrace{\frac{\partial C_{s a} U_{a}}{\partial x}}_{\text {Bulk Flow }}+\underbrace{\frac{v_{s a, \mathrm{ox}} r_{\mathrm{ox}}}{t_{\mathrm{a}}}}_{\text {Reaction }}
$$

\subsection{1-D Dynamic Energy Balance Equations}

The energy balance equations are written for the four differential control volumes of the fuel channel, air channel, PEN structure, and interconnect. The derivation of these equations is drastically simplified by the assumption of plug flow and lumped temperature in the direction transverse to the bulk flow. The derivation of the energy equations was completed while keeping in mind where the reaction chemistry will occur, and at what temperatures the species enthalpies must be evaluated at based on the species transport direction.

The fuel energy equation captures the transient internal energy storage term associated with composition and temperature variations, and spatially resolves the energy terms associated with bulk flow, convection, and diffusion. The heat generated from the heterogeneous and electrochemical reactions is assumed to be released in the PEN structure where the TPB and nickel catalyst surfaces are contained. From an energy balance on the fuel channel differential control volume a partial differential equation can be derived (7), where $\bar{u}_{\mathrm{f}}$ and $\bar{h}_{\mathrm{f}}$ are physical properties of the fuel mixture. The convection coefficients $\left(h_{\mathrm{f}, \text { pen }}, h_{\mathrm{f}, \text { int }}\right)$ are determined from the Nusselt number and fluid thermal conductivity.

$$
\underbrace{\frac{\partial \bar{u}_{\mathrm{f}} C_{\mathrm{f}}}{\partial t}}_{\text {Storage }}=-\underbrace{\frac{\partial C_{\mathrm{f}} U_{\mathrm{f}} \bar{h}_{\mathrm{f}}}{\partial x}}_{\text {BulkFlow }}
$$

$$
-\underbrace{\frac{1}{t_{\mathrm{f}}}\left(h_{\mathrm{f}, \text { pen }}\left(T_{\mathrm{f}}-T_{\mathrm{pen}}\right)+h_{\mathrm{f}, \text { int }}\left(T_{\mathrm{f}}-T_{\mathrm{int}}\right)\right)}_{\text {Convection }}-\underbrace{\frac{1}{t_{\mathrm{f}}} q_{\mathrm{f}_{\mathrm{M}}^{\prime \prime}}^{\prime \prime}}_{\text {Diffusion }}
$$

The calculation of the thermal energy that accompanies diffusive mass transport of a species $\left(q_{\mathrm{f}_{\mathrm{M}}}^{\prime \prime}\right)$ is completed through determining the net consumption or production. 
The species enthalpies are evaluated at the fuel channel temperature weather they are consumed or produced. This calculation enables the heat of reaction to occur within the PEN structure, while still allowing thermal communication between the fuel channel and PEN through diffusive mass transport. Equations (8) and (9) mathematically describe this process.

$$
\begin{gathered}
q_{\mathrm{f}_{\mathrm{M}}}^{\prime \prime}=\sum_{s f} q_{s f_{\mathrm{M}}}^{\prime \prime} \\
q_{s f_{\mathrm{M}}}^{\prime \prime}=\sum_{k} v_{s f, k} r_{k} \bar{h}_{s f}\left(T_{\mathrm{f}}\right)
\end{gathered}
$$

The air channel energy balance is derived in a similar fashion to the fuel channel. However, since the mass transport of oxygen from the air channel to the PEN structure will only occur in the direction where the cell will generate a positive current density, the enthalpy $\left(\bar{h}_{\mathrm{O}_{2}}\right)$ associated with mass transfer may be evaluated at the temperature of the air channel. This equation captures the same transient and spatially resolved terms as previously mentioned in the fuel channel energy equation.

$$
\begin{gathered}
\underbrace{\frac{\partial \bar{u}_{\mathrm{a}} C_{\mathrm{a}}}{\partial t}=-\underbrace{\frac{\partial C_{\mathrm{a}} U_{\mathrm{a}} \bar{h}_{\mathrm{a}}}{\partial x}}_{\text {BulkFlow }}}_{\text {Storage }} \\
-\underbrace{\frac{1}{t_{\mathrm{a}}\left(h_{\mathrm{a}, \mathrm{pen}}\left(T_{\mathrm{a}}-T_{\mathrm{pen}}\right)+h_{\mathrm{a}, \text { int }}\left(T_{\mathrm{a}}-T_{\mathrm{int}}\right)\right)}-\underbrace{\frac{1}{t_{\mathrm{a}}} q_{\mathrm{M}}^{\prime \prime}}_{\text {Diffusion }}}_{\text {Convection }} \\
q_{\mathrm{a} \mathrm{M}}^{\prime \prime}=v_{\mathrm{ox}, \mathrm{O}_{2}} r_{\mathrm{ox}} \bar{h}_{\mathrm{O}_{2}}\left(T_{\mathrm{a}}\right)
\end{gathered}
$$

The derivation of the energy equation for the PEN structure has a multitude of assumptions to simplify its numerical evaluation. Aside from the previously mentioned lumped temperature in the direction transverse to the bulk flow, the heat capacity of the gas phase species present in the porous media of the anode and cathode are assumed to be negligible compared to the heat capacity of the solid $\left(c_{\text {pen }}\right)$. Additionally, the thermal conductivity of the PEN structure $\left(k_{\text {pen }}\right)$ is assumed to be uniform for all lay- 
ers, where the thermal conductivity of the gas phase species will not alter the overall thermal conductivity. The terms associated with mass transfer from the channels to the porous media are calculated from the aforementioned method of the fuel and air channel energy equations. This calculation is based on the assumption that the convection coefficient between the gas phase inside the porous media and solid is large enough for an isothermal assumption between phases. Equation (12) presents the differential energy equation for the PEN,

$$
\begin{aligned}
\underbrace{c_{\text {pen }} \rho_{\text {pen }} \frac{\partial T_{\text {pen }}}{\partial t}}_{\text {PENInternal Energy }}= & \underbrace{\frac{\partial}{\partial x}\left(k_{\text {pen }} \frac{\partial T_{\text {pen }}}{\partial x}\right)}_{\text {Conduction }} \\
& +\underbrace{\frac{1}{t_{\text {pen }}}\left(h_{\mathrm{f}, \text { pen }}\left(T_{\mathrm{f}}-T_{\text {pen }}\right)+h_{\mathrm{a}, \text { pen }}\left(T_{\mathrm{a}}-T_{\text {pen }}\right)\right)}_{\text {Convection }} \\
& +\underbrace{\frac{1}{t_{\text {pen }}}\left(q_{\mathrm{f}_{\mathrm{M}}^{\prime \prime}}^{\prime \prime}+q_{\mathrm{a}}^{\prime \prime}\right)}_{\text {Diffusion }}-\underbrace{\frac{j V}{t_{\text {pen }}}}_{\text {Electrochemical Oxidation }} .
\end{aligned}
$$

The energy balance of the interconnect is derived similarly, where the temperature gradient transverse to the bulk flow will be insignificant and the problem reduces to a simple 1-D conduction with convection to the adjacent gas channels.

$$
\begin{aligned}
\underbrace{c_{\text {int }} \rho_{\text {int }} \frac{\partial T_{\text {int }}}{\partial t}}_{\text {Interconnect Internal Energy }}=\underbrace{\frac{\partial}{\partial x}\left(k_{\text {int }} \frac{\partial T_{\text {int }}}{\partial x}\right)}_{\text {Conduction }} \\
+\underbrace{\frac{1}{t_{\text {int }}\left(h_{\mathrm{f}, \text { int }}\left(T_{\mathrm{f}}-T_{\text {int }}\right)+h_{\mathrm{a}, \text { int }}\left(T_{\mathrm{a}}-T_{\text {int }}\right)\right)}}_{\text {Convection }}
\end{aligned}
$$

\subsection{1-D Momentum Balance}

The momentum balance developed for SOFCs by Kee et al. [27] for Hagen-Poiseuille channel flow can be implemented in dynamic channel-level models, where the dynamics of the momentum balance equation have been shown to be of relatively low 
importance by Schmidt [51]. Since the flows in the air and fuel channels fall in the laminar regime, the product of the Reynolds number and friction factor $(\operatorname{Re} f)$ can be determined to be a constant. Shah and London [52] give the friction factor for a rectangular duct, Equation (15), where the static momentum balance is taken as derived by Kee et al. [27] which is dependent on the aspect ratio of the channel (Ar), hydraulic diameter of the channel $\left(D_{\mathrm{c}}\right)$, fluid viscosity $(\mu)$, and bulk pressure gradient $\left(\frac{d p}{d x}\right)$.

$$
\begin{gathered}
U=-\frac{1}{\operatorname{Re} f} \frac{D_{\mathrm{c}}^{2}}{2 \mu} \frac{d p}{d x} \\
\operatorname{Re} f=14.227+1402.5\left(\frac{1+A r(\sqrt{2}-1)}{4(1+A r)}-\frac{\sqrt{2}}{8}\right)^{1.9}
\end{gathered}
$$

\subsection{1-D Internal Reforming Reactions}

In an SOFC, internal reforming of hydrocarbon fuel sources can be accomplished on the active nickel surfaces of the anode. The two key pathways associated with the SOFC internal reforming are methane steam reforming and water-gas-shift. Even though it is known that some dry reforming can occur in SOFCs [19], here it is assumed that the dominate pathway will be steam reforming due to the high steam-to-carbon ratios used in the simulations $(S / C=2.0)$.

The implementation of these reactions in the model requires the use of a global rate expressions, which were adopted from Timmermann et al. [54] for methane steam reforming ${ }^{1}$ and an arbitrarily fast rate expression to approach equilibrium for the watergas-shift reaction. Based on the external anode surface area, the rate expression was determined to be first order in methane, which is consistent with the detailed catalytic studies of Wei and Iglesia [58]. The pre-exponential and apparent activation energy are based on the temperature of the PEN structure. The purpose of apparent activa-

\footnotetext{
${ }^{1}$ The pre-exponential values reported by Timmermann et al. [54] have been modified such that the rate is based on the electrochemically active area of the cell rather than the exposed anode area of a cell with ribbed interconnects.
} 
tion energy is to have a rate expression which allows for mass transport limitations on the reforming rate to be taken into account. Timmermann showed that the reforming rate of the cell may be limited through the heterogeneous kinetics or mass transport where a change in the slope of the Arrhenius plot indicates different limiting steps. From the available internal reforming rate expressions utilized for SOFC modeling $[60,59,2,58,15,9,10,29,6,14,45]$, the work of Timmermann was determined to be most appropriate because the rate expression was developed at typical conditions of SOFC operation in an integral type reactor. An in-depth review of methane reforming rate expressions has been conducted by Mogensen et al. [37], where significant disagreement in the rate and activation energy of steam methane reforming between studies was reported.

$$
\begin{gathered}
r_{\mathrm{sr}}=k_{\mathrm{sr}} p_{\mathrm{CH}_{4}, \mathrm{~s}}\left(1-\frac{p_{\mathrm{H}_{2}, \mathrm{~s}}^{3} p_{\mathrm{CO}, \mathrm{s}}}{K_{\mathrm{sr}}^{\mathrm{eq}} p_{\mathrm{CH}_{4}, \mathrm{~s}} p_{\mathrm{H}_{2} \mathrm{O}, \mathrm{s}}}\right) \\
k_{k}=k_{\mathrm{o}, k} \exp \left(\frac{-E_{\mathrm{a}, k}}{R T_{\mathrm{pen}}}\right)
\end{gathered}
$$

The water-gas-shift reaction is typically observed to be in equilibrium due to fast kinetics [58], thus the rate expression can be assumed to be first order in carbon monoxide with provisions for the approach to equilibrium. The rate constant can be assumed to be an arbitrarily high value.

$$
r_{\mathrm{wgs}}=k_{\mathrm{wgs}} p_{\mathrm{CO}, \mathrm{s}}\left(1-\frac{p_{\mathrm{H}_{2}, \mathrm{~s}} p_{\mathrm{CO}_{2}, \mathrm{~s}}}{K_{\mathrm{wgs}}^{\mathrm{eq}} p_{\mathrm{CO}, \mathrm{s}} p_{\mathrm{H}_{2} \mathrm{O}, \mathrm{s}}}\right)
$$

\subsection{1-D Electrochemical Submodel}

The derivation of the electrochemical submodel for the 1-D cell model relies on several assumption including; modeling the cell electrodes as equipotential surfaces, evaluating the mass transport processes as equimolar counter diffusion at constant pressure, and hydrogen is the only electrochemically active fuel species. The reversible cell volt- 
age can be calculated through evaluating the Nernst potential $\left(E_{\mathrm{N}}\right)$ at the exterior anode surface and the operating potential $\left(V_{\text {cell }}\right)$ can be calculated by reducing the Nernst potential by the concentration, activation and ohmic overpotentials. However, here the Nernst potential is taken from the partial pressures of species at the TPB $\left(p_{s f, \text { TPB }}\right)$. This method requires a simultaneous solution of the entire electrochemical submodel, however, the approach eliminates any ambiguity that may exist between the concentration and activation overpotential equations. The Nernst potential can be evaluated with Equation (19), where $\Delta G_{\mathrm{ox}}^{\mathrm{o}}$ is the change in Gibbs free energy of the oxidation reaction calculated at the local temperature of the PEN structure and the partial pressures of the hydrogen, steam, and oxygen are taken at the TPB. The Nernst potential can then be reduced by the activation $\left(\eta_{\text {act }}\right)$ and ohmic $\left(\eta_{\mathrm{ohm}}\right)$ overpotentials as given in Equation (20).

$$
\begin{gathered}
E_{\mathrm{N}}=\frac{-\Delta G_{\mathrm{ox}}^{\mathrm{o}}}{2 F}-\frac{R T_{\mathrm{pen}}}{2 F} \ln \left(\frac{p_{\mathrm{H}_{2} \mathrm{O}, \mathrm{TPB}} / p_{\mathrm{o}}}{p_{\mathrm{H}_{2}, \mathrm{TPB}} / p_{\mathrm{o}}\left(p_{\mathrm{O}_{2}, \mathrm{TPB}} / p_{\mathrm{o}}\right)^{1 / 2}}\right) \\
V_{\text {cell }}=E_{\mathrm{N}}-\eta_{\text {act }, \text { an }}+\eta_{\text {act }, \mathrm{ca}}-\eta_{\mathrm{ohm}}
\end{gathered}
$$

\subsubsection{Activation Overpotential}

The activation overpotential accounts for the potential difference between the electrode and electrolyte phases due to the kinetics of the electrochemical reaction. The kinetics of the electrochemical oxidation reaction are similar to the kinetics of heterogeneous reactions in that an energy barrier exists which must be overcome for the reaction to proceed. Typically, the activation overpotential is represented with a global Butler-Volmer equation where it is widely known that the symmetry factors of the global charge transfer occurring in SOFCs will not sum to unity. This result is displayed in the Tafel plots of patterned anode and electrolyzer experiments [36, 38]. However, it is possible to develop a global Butler-Volmer equation for a rate limiting step approximation to an elementary charge transfer mechanism [63]. Here the rate limiting step is taken as the hydrogen spillover charge transfer step that has been shown 
in other works to be in good agreement with experimental data [18]. Additionally, a result of this formulation is the exchange current densities will be functions of both temperature and partial pressures of the electrochemically active species at the TPB. Since the adsorption and desorption reactions are typically taken to be in equilibrium, the partial pressures of species will directly impact the surface species coverages of the species involved in the rate limiting step. The modified Butler-Volmer formulation used here derived by Zhu et al. [63] is given in Equation (21), where $\beta_{\mathrm{a}, \text { an }}$ is the anode symmetry factor in the anodic direction of the rate limiting charge transfer step.

$$
\begin{aligned}
j_{\mathrm{an}}=j_{\mathrm{o}, \mathrm{an}}\left[\exp \left(\frac{\left(1+\beta_{\mathrm{a}, \mathrm{an}}\right) F \eta_{\mathrm{act}, \mathrm{an}}}{R T_{\mathrm{pen}}}\right)\right. & \\
& \left.-\exp \left(-\frac{\left(1-\beta_{\mathrm{a}, \mathrm{an}}\right) F \eta_{\mathrm{act}, \mathrm{an}}}{R T_{\mathrm{pen}}}\right)\right]
\end{aligned}
$$

The expression for the exchange current density can be shown to include constants such as the length of the three phase boundary, however, since many of these parameters are not measurable the parameter $j_{\mathrm{o} \text {,an }}^{\text {ref }}$ is taken as a fitting parameter. Additionally, the temperature dependent adsorption equilibrium constant of hydrogen on a nickel surface is needed. The work of Lapujoulade and Neil [31] can be used to obtain these values, where Zhu et al. [63] has formulated them as partial pressure desorption constants, which have high variations with temperature due to the large activation energy. In Equation (22) the partial pressure of the steam should be evaluated in atmospheres.

$$
\begin{aligned}
& j_{\mathrm{o}, \text { an }}=j_{\mathrm{o}, \mathrm{an}}^{\mathrm{ref}}\left(\frac{-E_{\mathrm{a}, \mathrm{an}}}{R T_{\mathrm{pen}}}\right) \\
& \frac{\left(p_{\mathrm{H}_{2}, \mathrm{TPB}} / p_{\mathrm{H}_{2}}^{*}\right)^{\beta_{c, \mathrm{an} / 2}}\left(p_{\mathrm{H}_{2} \mathrm{O}, \mathrm{TPB}}\right)^{1-\beta_{\mathrm{c}, \mathrm{an} / 2}}}{1+\sqrt{p_{\mathrm{H}_{2}, \mathrm{TPB} / p_{\mathrm{H}_{2}}^{*}}^{*}}}
\end{aligned}
$$




$$
p_{\mathrm{H}_{2}}^{*}=\frac{A_{\mathrm{H}_{2}} \Gamma^{2} \sqrt{2 \pi R T_{\mathrm{pen}} M_{\mathrm{H}_{2}}}}{\gamma_{\mathrm{o}}} \exp \left(\frac{-E_{\mathrm{a}, \mathrm{H}_{2}}}{R T_{\mathrm{pen}}}\right)
$$

The cathodic activation overpotential can be evaluated in a similar fashion using a rate limiting step approximation to an elementary charge transfer mechanism. The resulting equation has similar features, however, the symmetry factors will sum to one.

$$
\begin{aligned}
j_{\mathrm{ca}}=j_{\mathrm{o}, \mathrm{ca}}\left[\exp \left(\frac{\beta_{\mathrm{a}, \mathrm{ca}} F \eta_{\mathrm{act}, \mathrm{ca}}}{R T_{\mathrm{pen}}}\right)\right. & \\
& \left.-\exp \left(\frac{\left(\beta_{\mathrm{a}, \mathrm{ca}}-1\right) F \eta_{\mathrm{act}, \mathrm{ca}}}{R T_{\mathrm{pen}}}\right)\right]
\end{aligned}
$$

The exchange current density is expressed again as the product of temperature and partial pressure terms, where $j_{\mathrm{o}, \mathrm{ca}}^{\mathrm{ref}}$ is a fitting parameter. The oxygen adsorption equilibrium constants, determined by Zhu et al. [63], are taken from the work of Matsuzaki and Yasuda [34].

$$
\begin{gathered}
j_{\mathrm{o}, \mathrm{ca}}=j_{\mathrm{o}, \mathrm{ca}}^{\mathrm{ref}} \exp \left(-\frac{E_{\mathrm{a}, \mathrm{ca}}}{R T_{\mathrm{pen}}}\right) \frac{\left(p_{\mathrm{O}_{2}, \mathrm{TPB} / p_{\mathrm{O}_{2}}^{*}}\right)^{\beta_{\mathrm{a}, \mathrm{ca} / 2}}}{1+\sqrt{p_{\mathrm{O}_{2}, \mathrm{TPB} / p_{\mathrm{O}_{2}}^{*}}}} \\
p_{\mathrm{O}_{2}}^{*}=A_{\mathrm{O}_{2}} \exp \left(-\frac{E_{\mathrm{a}, \mathrm{O}_{2}}}{R T_{\mathrm{pen}}}\right)
\end{gathered}
$$

\subsubsection{Ohmic Overpotential}

The ohmic overpotential is the resistance of the cell to charge transport, which can be divided into ionic and electronic components. The ionic portion accounts for the majority of the ohmic overpotential, due to the transport resistance of oxygen ions across the electrolyte phase. Additionally, the electrons that are released from the electrochemical oxidation are conducted from the TPB through the electrode phase of the anode until reaching the current collection device, which is typically a nickel mesh on the external anode surface. 
An expression for the ohmic overpotential can be written as the product of the local charge transfer resistance and local current density. The charge transfer resistance can be expressed as the sum of the inverse conductivities $(\sigma)$ of the anode, cathode, and electrolyte.

$$
\begin{gathered}
\eta_{\mathrm{ohm}}=R^{\prime \prime} j \\
R^{\prime \prime}=\left(\frac{t_{\mathrm{an}}}{\sigma_{\mathrm{an}}}+\frac{t_{\mathrm{elec}}}{\sigma_{\mathrm{elec}}}+\frac{t_{\mathrm{ca}}}{\sigma_{\mathrm{ca}}}\right)
\end{gathered}
$$

\subsubsection{Mass Transport Model}

Concentration gradients will begin to develop in the porous media as current is drawn from the cell due to mass transport resistances. For the simple case of equimolar counter diffusion, a linear drop in hydrogen (increase in steam) partial pressure will be experienced. The reduction (increase) in the species partial pressure will depend on the effective diffusivity, evaluated at the local PEN temperature, and be proportional to the local current density. The effective diffusivity of counter diffusing species can be calculated through the Bosanquet Equation (29), which combines the effects of Knudsen and binary diffusion.

$$
\mathscr{D}_{\mathrm{an}, \mathrm{ca}}^{\mathrm{eff}}=\left(\frac{1}{\mathscr{D}_{k, l}}+\frac{1}{\mathscr{D}_{\mathrm{Kn}}^{\mathrm{eff}}}\right)^{-1}
$$

The Knudsen diffusivity can be evaluated from Equation (30) which only depends on the average pore radius $\left(\mathrm{r}_{\mathrm{p}}\right)$ and temperature of the porous media. The binary diffusivities are evaluated by the method described by Poling et al. [46].

$$
\mathscr{D}_{\mathrm{Kn}}=\frac{2}{3} r_{\mathrm{p}} \sqrt{\frac{8 R T_{\mathrm{pen}}}{\pi M}}
$$

As explained by DeCaluwe et al. [13] and Epstein [16], the correction for a diffusivity in porous media regarding the physical interpretation of the tortuosity $(\tau)$ requires it to be squared such that the diffusivity is corrected for the increase in path length and 
the normal component of velocity.

$$
\mathscr{D}^{\mathrm{eff}}=\frac{\phi}{\tau^{2}} \mathscr{D}
$$

For the case of equimolar counter diffusion, the drop in partial pressure of hydrogen and increase in partial pressure of steam can be evaluated by Equations (33) and (32), as presented by Aguiar et al. [4]. This formulation assumes that the total pressure throughout the depth of the anode will remain constant and the effective diffusivity for each species will be the same. However, since steam and hydrogen have significantly different molecular weights a pressure gradient will develop across the anode for counter diffusion to occur based on Graham's Law $\left(\dot{N}_{1} / \dot{N}_{2}=\sqrt{M_{2} / M_{1}}\right)$.

$$
\begin{gathered}
p_{\mathrm{H}_{2} \mathrm{O}, \mathrm{TPB}}=p_{\mathrm{H}_{2} \mathrm{O}, \mathrm{s}}+\frac{R T_{\text {pen }} t_{\mathrm{an}}}{2 F \mathscr{D}_{\mathrm{an}}^{\text {eff }}} j \\
p_{\mathrm{H}_{2}, \mathrm{TPB}}=p_{\mathrm{H}_{2}, \mathrm{~s}}-\frac{R T_{\text {pen }} t_{\mathrm{an}}}{2 F D_{\mathrm{an}}^{\text {eff }}} j
\end{gathered}
$$

For the cathode, the diffusion of oxygen will result in an exponential drop in the partial pressure. Since this is not a case of counter diffusion, the mass transport will result in a pressure gradient being established across the cathode. The partial pressure of oxygen at the TPB can be calculated from Equation (34). This equation was determined to be in good agreement with the prediction of the DGM for a single species diffusion through porous media.

$$
p_{\mathrm{O}_{2}, \mathrm{TPB}}=p_{\mathrm{a}, \mathrm{s}}-\left(p_{\mathrm{a}, \mathrm{s}}-p_{\mathrm{O}_{2}, \mathrm{~s}}\right) \exp \left(\frac{R T_{\mathrm{pen}} t_{\mathrm{ca}}}{4 F D_{\mathrm{ca}}^{\text {eff }} p_{\mathrm{a}, \mathrm{s}}} j\right)
$$

Additionally, a mass transfer resistance will be experienced in SOFCs, where the partial pressure of species at the porous anode surface $\left(p_{s f, \mathrm{~s}}\right)$ and channel $\left(p_{s f}\right)$ at the TPB due to bulk diffusion. The method described by Timmermann et al. [54] for evaluating bulk diffusion in SOFC channels has been adopted here. Where $\beta_{s f}$ is the 
mass transfer coefficient given by equation (35), $\mathscr{D}_{s f, \mathrm{M}}$ is the species mixture diffusion coefficient, and $d_{\mathrm{h}, \text { anode }}$ is the anodic hydraulic diameter.

$$
\begin{gathered}
\frac{\beta_{s f}}{R T_{\text {pen }}}\left(p_{s f}-p_{s f, \mathrm{~s}}\right)+\sum_{k} v_{s f, k} r_{k}=0 \\
\beta_{s f}=\frac{3.7 \mathscr{D}_{s f, \mathrm{M}}}{d_{\mathrm{h}, \text { anode }}}
\end{gathered}
$$

\section{4. 'Quasi' 2-D Physically Based Dynamic Modeling Methodology}

If the coupled effects of the mass transport, heterogeneous chemical reaction, and electrochemical reaction are to be captured, a 'quasi' 2-D model can be developed. The coupled effects can be taken into account through an additional mass balance, which will resolve the species concentrations throughout the depth of the anode. Here a 1-D plug flow model is retained for the fuel and air channel, however, the anode sublayer has been discretized giving rise to the second dimension. Many of the previously developed conservation equations can be implemented into this modeling methodology, however, changes are required for the fuel channel mass balance, anode mass balance, diffusion heat transport equations, and mass transport and electrochemical models.

\section{1. 'Quasi' 2-D Dynamic Mass Balance Equations}

The dynamic species balance equation for the air channel (6), derived for the 1-D modeling case, can be adopted for the 'quasi' 2-D model. However, the fuel channel species balance is modified to include the species flux at the boundary between the gas channel and porous media. This term will no longer be the summation of the reaction rates, but rather the molar flux at the fuel channel porous anode interface calculated from the DGM.

$$
\underbrace{\frac{\partial C_{s f}}{\partial t}}_{\text {Species Concentration }}=-\underbrace{\frac{\partial C_{s f} U_{\mathrm{f}}}{\partial x}}_{\text {BulkFlow }}-\underbrace{\frac{1}{t_{\mathrm{f}}} J_{\mathrm{dif}, s f}}_{\text {Diffusion }}
$$


An additional species balance is necessary for transport through the porous media transverse to the bulk channel flow. This equation adds the second dimension to the model where the species diffusion is evaluated throughout the anode support. The porous media diffusion in the streamwise direction can be neglected due to the concentration gradients in this direction being much lower than that experienced transverse to the bulk flow. The species balance for the cathode channel gas is unchanged.

$$
\underbrace{\phi_{\mathrm{an}} \frac{\partial C_{\mathrm{an}, s f}}{\partial t}}_{\text {SpeciesConcentration }}=-\underbrace{\frac{\partial J_{\mathrm{dif}, s f}}{\partial y}}_{\text {Diffusion }}+\underbrace{\sum_{k} v_{k, s f} r_{k}}_{\text {Reaction }}
$$

\section{2. 'Quasi' 2-D Dynamic Energy Balance Equations}

The dynamic energy balance Equations (7), (10), (12), and (13) derived for the 1-D modeling case can be adopted for the 'quasi' 2-D model. However, the expressions in the fuel channel and PEN energy balances for the thermal energy associated with mass transport are modified. Since the reforming occurs throughout the depth of the anode, the net reaction rate cannot be simply summed, but rather the species flux at the external anode surface $\left(J_{\mathrm{dif}, s f}\right)$ can be taken from the DGM.

$$
\begin{gathered}
q_{\mathrm{f}_{\mathrm{M}}}^{\prime \prime}=\sum_{s f} J_{\mathrm{dif}, s f} h_{s f}\left(T_{\mathrm{f}}\right) \\
q_{\mathrm{a}_{\mathrm{M}}}^{\prime \prime}=r_{\mathrm{ox}} h_{\mathrm{O}_{2}}\left(T_{\mathrm{a}}\right)
\end{gathered}
$$

\section{3. 'Quasi' 2-D Internal Reforming Reactions}

The methane steam reforming and water-gas-shift rate expressions take the same functional form as given in the 1-D modeling case (Equations (16) and (18)), however, the pre-exponential and activation energy terms will change. The temperature variations in the steam reforming pre-exponential and activation energy in the 1-D model will no longer be present because the effect of porous media mass transport on the partial pressures of the species entering the rate expression is explicitly evaluated through 
the DGM. The values given in Table 2 were determined by Kromp et al. [30].

\section{4. 'Quasi' 2-D Electrochemical Submodel}

The electrochemical model will take the same form as given by Equations (20), (19), (21), (24), (27), and (34), however, the mass transport model used to evaluate the partial pressures of steam and hydrogen at the TPB will be different. The DGM (41) can be used in conjunction with the anode species balance and internal reforming rate expressions to determine the partial pressures of species at the TPB. Here the reforming is able to distort the concentration profiles of species throughout the depth of the anode, relaxing the assumption of equimolar counter diffusion and heterogeneous chemistry occurring on the external anode surface.

\subsubsection{Porous Media Mass Transport}

The DGM [33] is used to calculate the species flux terms in equation (38). The contribution of the binary and Knudsen diffusion terms, as well as the viscous flow are taken into account. As Equation (41) shows, the DGM forms an implicit relationship between the molar flux, and concentration and pressure gradients existing in the porous anode.

$$
\sum_{l \neq k} \underbrace{\frac{C_{l} J_{k}-C_{k} J_{l}}{C_{\mathrm{T}} D_{k, l}^{\text {eff }}}}_{\text {Ordinary }}+\underbrace{\frac{J_{k}}{D_{k, \mathrm{Kn}}^{\text {eff }}}}_{\text {Knudsen }}=
$$

$$
-\underbrace{\nabla C_{k}}_{\text {Concentration Gradient }}-\underbrace{\frac{C_{k}}{D_{k, \mathrm{Kn}}^{\mathrm{eff}}} \frac{B_{\mathrm{g}}}{\mu} \nabla p}_{\text {Darcy Term }}
$$

The permeability $\left(B_{\mathrm{g}}\right)$ of the porous anode can be evaluated by the Kozeny-Carman relationship Equation (42), which is a relationship between the porosity $\left(\phi_{\mathrm{an}}\right)$, average 
particle diameter $\left(d_{\mathrm{p}}\right)$ and tortuosity $\left(\tau_{\mathrm{an}}\right)$ of the porous media.

$$
B_{\mathrm{g}}=\frac{\phi_{\mathrm{an}}^{3} d_{\mathrm{p}}^{2}}{72 \tau_{\mathrm{an}}^{2}\left(1-\phi_{\mathrm{an}}\right)^{2}}
$$

The bulk mass transport model used for the 'quasi' 2-D model is similar to the 1-D model, however, the species flux at the anode surface can be explicitly evaluated so Equation (35) is replaced by Equation (43). This equation also provides one of the necessary boundary conditions for the solution to the DGM, and the other is provided by the local current density.

$$
\frac{\beta_{s f}}{R T_{\mathrm{pen}}}\left(p_{s f}-p_{s f, \mathrm{~s}}\right)-J_{\mathrm{dif}, s f}=0
$$

\section{Electrochemical Modeling Parameters}

The solution to the models are largely based on the knowledge of the parameters associated with the electrochemical, heterogeneous chemistry, and mass transport modeling equations. Although some parameters are available through measurement, many of the parameters are taken as fitting parameters, such as the tortuosity and reference exchange current densities. The parameters employed here are displayed in Table 3 and adopted from several prior modeling efforts.

\section{Model Verification}

Two approaches were taken to verify the electrochemical submodel and reforming rate expression against experimental data. The electrochemical submodel was verified using experimental data from humidified hydrogen and humidified methane-fueled button cells. The reforming rate expression was verified using fuel channel composition data obtained from multiple gas chromatography measurements along the length of an integral type reactor [30]. 


\subsection{Electrochemical Model Verification}

The button cell data presented by Lin et al. [32] for a cell fueled on humidified hydrogen or humidified methane was used to verify the model. The geometry of the button cell consisted of an anode diameter of $19 \mathrm{~mm}$ and cathode area of $0.5 \mathrm{~cm}^{2}$. A simple button cell model was developed which implements the electrochemical model of either the 1-D or 'quasi' 2-D channel-level model where the gas compartments are taken to be continuously stirred tank reactors fed at the conditions specified. A steadystate mass balance allows for the calculation of the fuel compartment compositions. The channel-level differential equations were not solved in this analysis where the goal was to verify the electrochemical model alone. This approach simplifies the verification process where fuel depletion along the length of the channel and temperature gradient effects are not experienced in a button cell as they are in a tubular or planar SOFC.

In order to simplify the geometry of the button cell, the anode is divided into two regions where the cell will and will not be electrochemically active due to the smaller cathode area. In these two regions the boundary condition at the anode fuel compartment interface will be the same, however, the boundary condition at the anode electrolyte interface will be different. For the electrochemically active area, the species flux at the anode electrolyte boundary will be proportional to the current density, and for the non-electrochemically active area the boundary species flux will be equal to zero. This allows for fuel reforming to occur over the entire area of the anode, however, the electrochemistry will be isolated to the active area in the center of the cell.

The verification of the humidified hydrogen cell model to the experimental data is displayed in Figure 4. The modeling parameters found in literature, displayed in Table 3 , were found to be in good agreement with the experimental data of the hydrogen fueled button cell, where the porosity and tortuosity were calibrated for the 2-D model to fit the experimental. These two parameters give the effective diffusivity (equation (31)) and can be calibrated against the button cell data to predict the limiting current density, 
where a direct measurement of tortuosity is typically not possible. The calibration undertaken for the 2-D model and the parametes were held constant for the 1-D model to obtain a quantitative comparison of the models. However, an additional calibration is possible for the 1-D model to the experimental data where a lower value of porosity enables better agreement with the data. Both 1-D and 2-D models are capable of accuratly representing the data of a hydrogen fueled button cell. For the hydrogen steam data (Figure 4), both models are demonstrated to agree well with the experimental data, however, the models deviate slightly from the experimental open circuit potentials, and the low operating temperature data. This is speculated to occur because of possible non-isothermal conditions or species concentration gradients within the fuel compartment and cell; higher fidelity button cell models have been developed which look to resolve these issues $[17,21]$. However, since the modeling effort here is directed toward channel-level model verification where the species concentration gradients within the fuel compartment are not resolved these effects are not explored further. The differences between current voltage predictions of the 1-D and 'quasi' 2-D models arise from the inclusion of the viscous term in the DGM where a pressure gradient is allowed to be established across the anode limiting the cell to a lower limiting current density.

Further model verification was completed for the cell operated on humidified methane. The electrochemical modeling parameters, which were determined to be in good agreement with the hydrogen fueled cell, were held constant to verify the model when operating on a methane fuel source. Figure 5 reveals the limitations of a 1-D model where the reforming is only allowed to occur on the external anode surface, and the reformed fuel must diffuse through the anode to the TPB. The 'quasi' 2-D model allows for the diffusion of all fuel species into the anode, where the source of steam involved in the reforming reactions is provided by the electrochemical reactions at the TPB. Since the steam involved in the reforming process is the limiting reactant, it becomes important to model the reforming as occurring close to the anode. Furthermore, using 
the lower value of porosity calibrated for the 1-D model on hydrogen fuel only causes the predictions of the 1-D model to further deviate from the experimental data. Neglecting the coupled effects of the reforming reactions and mass transport results in larger overpotentials, especially at high operating temperatures and current densities. This difference is attributed to the increase in the rate of reforming and increased mass transport limitations on the cell at higher temperatures and current densities.

To further demonstrate the modeling differences, plots of the species distributions within the anode are displayed in Figure 6 for the indicated operating points A and B on Figure 4 and Figure 5 respectively. At operating point A the species profile comparison demonstrates the modeling agreement for the partial pressure of hydrogen at the TPB, however, there exists differences in the predicted steam partial pressures at the TPB. Differences in either hydrogen or steam partial pressure lead to a difference in the Nernst potential of the model. The difference in the steam partial pressure arises from the diffusion models implemented. In the 1-D model, the diffusion submodel does not capture the pressure gradient that is established across the anode. This result causes the 1-D model to have a higher Nernst potential than the 'quasi' 2-D model. This difference accounts for the slightly higher operating potential that is predicted by the 1-D model, however, the partial pressure of steam at the TPB also influences the anodic activation overpotential, due to the exchange current density being a function of the partial pressure of steam at the TPB. Thus the difference in Nernst potential is greater than the difference in operating potential because increases in the partial pressure of steam at the TPB reduces Nernst potential as well as the anodic activation overpotential.

At operating point $\mathrm{B}$ for the methane and steam fueled cell, the 1-D model predictions of the gas phase species in the fuel compartment are indicated by the symbols at the anode surface. Since the fuel reforming in the 1-D model is only allowed to occur on the outer anode surface, the species profiles throughout the depth of the an- 
ode are only resolved for hydrogen and steam. It is evident, from the species profiles throughout the depth of the anode, that the performance of the 1-D model is inhibited by modeling the reforming of methane as only occurring on the surface of the anode. In the 'quasi' 2-D model, the methane is allowed to diffuse through the depth of the anode and react with the steam that is produced by the electrochemical reactions at the TPB. This leads to increased hydrogen and decreased steam partial pressures at the TPB where a higher Nernst potential will be experienced. Additionally, the water-gasshift reaction is allowed to occur throughout the depth of the anode in the 'quasi' 2-D model. Since the reactants are produced from the steam reforming and electrochemical reactions, this reaction will lead to an additional increase in the hydrogen partial pressure at the TPB. For the methane fueled button cell the 'quasi' 2-D model is able to more accurately represent the data. Given that fuel starvation is such a critical concern during dynamic load change, these results illustrate the importance of resolving the physicochemical phenomena in the anode. Prediction of higher hydrogen concentration in the TPB zone is also noteworthy because this suggest a potentially more robust SOFC response to dynamic load change.

\subsection{Channel-Level Model Reforming Verification}

The reforming rate expressions of Timmermann and Kromp can be compared to the channel gas chromatography data provided [30] to verify the reforming rate expression and plug flow model. The experiments were conducted with no electrochemical reactions and gas chromatography was implemented at several locations along the length of the cell to determine the rate of the steam reforming and water-gas-shift reactions. The experimental step up consisted of a cell $4 \mathrm{~cm}$ in length with a Ni/8YSZ anode. Channel dimensions were $1.5 \mathrm{~mm}$ by $1.5 \mathrm{~mm}$ and an interconnect rib thickness $1.1 \mathrm{~mm}$.

The modeling results compared to the experimental gas chromatography data are displayed in Figure 7 for a single temperature and gas composition. Both models are shown to be in good agreement with each other and the experimental data. In order 
to make comparisons at various gas compositions and temperatures, the methane conversion, given by Equation (44), of the two models was compared varying the inlet gas compositions and cell temperature. The results of the comparison are displayed in Figure 8, where reforming rate expressions of the models are shown to be in agreement for the operating temperature range of interest. It is important to note that the simulations and experiments here are based on an isothermal cell with no electrochemistry, thus the coupled interactions of the mass transport, heterogeneous chemistry, and electrochemistry do not influence the results. The results have also been compared to the limiting case of a thermodynamic equilibrium composition, which would be the result of infinitely fast kinetics and no mass transport limitations. The difference between the equilibrium and kinetic results indicate the importance of a model capturing these phenomena.

$$
X_{\mathrm{CH}_{4}}=\frac{\dot{N}_{\mathrm{CH}_{4}, \text { in }}-\dot{N}_{\mathrm{CH}_{4}, \text { out }}}{\dot{N}_{\mathrm{CH}_{4}, \text { in }}}
$$

\section{Steady-State Channel-Level Modeling}

The previous sections have focused on model comparison and verification of a simplified form of the modeling equations adapted to a button cell application. The remainder of the document focuses on the comparison of the complete channel-level 1-D and 'quasi' 2-D models.

\subsection{Channel-Level Modeling Parameters}

In order to solve the set of modeling equations, basic parameters regarding the geometry of the cell and physical properties of the solids are required. Table 4 provides a summary of the parameter specifications employed in the simulations. The parameters were kept as general as possible considering an anode-supported cell with a square platform. The interconnects are taken to be metallic, consistent with intermediate temperature SOFC construction, and the physical properties have been taken from a previous study [4]. 
The inlet fuel composition was determined based on a steam-to-carbon ratio and the percent completion of the steam reforming reaction. The water-gas-shift reaction is taken into account as well by assuming equilibrium at the inlet fuel temperature specified.

The derived equations for the two models form a system of differential algebraic equations which were solved using gPROMS ModelBuilder [1]. A finite difference method has been implemented to spatially resolve the partial differential equations, where 100 nodes in the streamwise direction for both models and 10 nodes in the direction transverse to the bulk flow for the 'quasi' 2-D model, results in grid independence.

Boundary conditions for the model must be specified in order to obtain a solution. The modeling inputs and boundary conditions taken here are the gas channel inlet temperatures, inlet compositions, and outlet pressures. Fuel and air flow rates were determined through the specification of the fuel utilization, air ratio $(A R)$, and average current density of the cell.

$$
A R=\frac{4 F \dot{N}_{\mathrm{O}_{2}, \text { in }}}{j A_{\text {cell }}}
$$

Verification of the model for the counter-flow configuration is presented in Figures 9 and 10 . The simulations were performed for a partially pre-reformed (10\%) methanefueled cell where the fuel flow rate and nominal cell temperature were varied to verify the polarization characteristics of the channel-level model.

Figure 9 depicts the effects of fuel flow rate on the limiting current density of the cell. The molar flow rate of the fuel was held constant over the entire current density, and was determined by specifying the fuel utilization at $5000 \mathrm{~A} \mathrm{~m}^{-2}$ as indicated on the plot. Lower levels of fuel utilization correspond to higher molar flow rates of fuel. As expected, the limiting current density of the cell is directly dependent on the molar flow rate of the fuel. For increases in the fuel molar flow rate the limiting current density increases from approximately 6000 to $7800 \mathrm{~A} \mathrm{~m}^{-2}$. 
The verification of the nominal cell temperature effect on the polarization curve was completed through varying the fuel and air inlet temperature as a function of current density in order to hold the nominal cell temperature constant. Figure 10 displays the effect of nominal cell temperature on the polarization characteristic of the cell. The molar flow rate of the fuel was held constant by setting the value where $75 \%$ utilization will occur at a current density of $5000 \mathrm{~A} \mathrm{~m}^{-2}$. The ohmic losses of the cell increase as the nominal temperature of the cell is decreased due to the temperature dependent ionic conductivity of the electrolyte. Decreases in temperature from $1123 \mathrm{~K}$ to $1023 \mathrm{~K}$ show a much lower impact than the corresponding reduction from $1023 \mathrm{~K}$ to $923 \mathrm{~K}$ due to the ionic conductivity's exponential dependence on temperature.

In the cell level simulations that were conducted for the verification of the channellevel model, both 1-D and 'quasi' 2-D modeling methodologies were also found to be in good agreement over the desired operating range of an SOFC stack. At high current densities, which approach the limiting value, differences in the models begin to appear, however, operating a stack or system in this regime is unlikely. The electrochemical performance of both channel-level modeling methodologies is not significantly different for the conditions explored for channel-level modeling.

\subsection{Modeling Comparison}

Comparisons of both channel-level modeling methodologies were completed in co and counter-flow geometries. Differences in the peak PEN temperature, maximum PEN temperature, and maximum PEN temperature gradient were explored because the temperature distribution of the cell influences the thermal stresses and electrochemical degradation [41, 42]. Since the major difference between the 1-D and 'quasi' 2-D modeling methodologies is the representation of the internal reforming process, the effect of pre-reforming is an operational variable to be investigated.

The results for the predicted PEN temperature and current density distribution for high levels of internal reforming in co- and counter-flow are displayed in Figure 11 
and Figure 12, respectively. For the co-flow case both models predict similar distributions for the PEN temperature and current density away from the entrance region of the cell. Figure 11 shows that in the entrance region of the cell the anode partial pressures of $\mathrm{H}_{2}$ and $\mathrm{H}_{2} \mathrm{O}$ at the TPB are significantly different. This causes the models to predict different Nernst potentials in the reforming region leading to a higher current density for the 'quasi' 2-D model. Since the electrochemical oxidation of $\mathrm{H}_{2}$ at the TPB is exothermic, the observed increase in current density results in a slight PEN temperature increase. However, since internal reforming occurs over a low temperature region of the cell, the modeling methodology does not impact the prediction of the maximum PEN temperature gradient or peak cell temperature. Additionally, there is no significant electrochemical performance difference between the models, where the 1-D model predicts an operating voltage of $0.7501 \mathrm{~V}$ compared to the $0.7507 \mathrm{~V}$ from the 'quasi' 2-D model. Thus, one conclusion is that in a co-flow configuration, a 1-D model is sufficient for capturing the PEN temperature distribution, even with high levels of internal reforming. In a future section the model differences will be shown to decrease with increasing amounts pre-reforming.

For the counter-flow configuration displayed in Figure 12, differences between the models become more pronounced. Temperature and current density distributions over the entrance region of the cell are significantly different, as well as the peak temperature and maximum temperature gradient of the cell. As displayed in the anode species profile plots, differences exist between the models for the prediction of partial pressures of $\mathrm{H}_{2}$ and $\mathrm{H}_{2} \mathrm{O}$ at the TPB. This difference results in the Nernst potential difference previously mentioned, however, the counter-flow operation produces a higher PEN temperature over the entrance region of the cell where the peak PEN temperature and maximum temperature gradient exist. Due to the coupled interactions of the reforming, mass transport, and electrochemistry occurring in this region, the model prediction of the maximum temperature gradient, and peak PEN temperature will be 
affected by the modeling methodology. The increased current density over the entrance of the 'quasi' 2-D model results in an increase in local temperature; however, since the average current density is held constant between the models, the increase in the entrance region must be accommodated by a complimentary decrease in current density over the remaining length. The decreased current of the 'quasi' 2-D model occurs around the peak current density. As displayed in the anode species profile plot in this region, the partial pressure of steam at the TPB is under predicted by the 1-D model due to the assumption of equimolar counter diffusion at constant pressure. The increased steam partial pressure will cause a reduction in the Nernst potential, lowering the peak local current density. The low peak current density also results in a lower peak cell temperature where the exothermic electrochemical oxidation of hydrogen occurs at a lower rate. However, the overall electrochemical performance of the models are still in good agreement where the 1-D model predicts an operating voltage of $0.8049 \mathrm{~V}$ and the 'quasi' 2-D model predicts an operating voltage of $0.8020 \mathrm{~V}$.

If high levels of internal reforming are eliminated from the counter-flow model where the fuel source entering cell is dominantly hydrogen, the predictions should be independent of modeling methodology, except for the slight differences between the diffusion models. The model predictions for a 99\% pre-reformed fuel are plotted in Figure 13. The PEN temperature and current density distribution are observed to be in good agreement between the two models. Additionally, the endothermic effect of the steam reforming reactions is no longer present since only small amounts of methane are allowed to enter the cell. The species profiles plotted throughout the depth of the anode show that linear species profiles are a good assumption for a highly pre-reformed fuel source. However, the rapid water-gas-shift reaction still occurs throughout the depth of the anode. In order for the water-gas-shift reaction to remain in equilibrium as the partial pressure of hydrogen is reduced and steam is increased, the reaction must proceed in the forward direction consuming steam and carbon monoxide and producing 
hydrogen and carbon dioxide. From the plots it is observed that the mass transport and electrochemical process causes the water-gas-shift reaction to produce hydrogen and consume steam throughout the anode depth. This effect will not be captured in the 1-D model since the water-gas-shift reaction is only held in equilibrium in the fuel channel. The differences in current density distribution that are observed between the model are due to the counter diffusion of the heavier water molecule, which establishes the pressure gradient across the anode. These effects are most prominent at high current densities where the pressure gradient will be the largest, as displayed in the button cell modeling results.

Although modeling methodology will effect the current density and temperature distribution for the counter-flow configuration, predictions of the fuel and air outlet composition and temperature, as well as the cell voltage are in good agreement. The steam reforming of methane will essentially go to equilibrium under the operating conditions of the model, thus the products will be determined by the operating temperature of the cell rather than the kinetic expression and mass transport model implemented. Additionally, the electrochemical models have been shown to be equivalent under conditions for a hydrogen and steam fueled cell. After the methane reforming has been completed in the entrance region of the cell, the temperature and current density profiles converge for both co-flow or counter-flow configurations and modeling differences cease to exist.

To further explore the modeling differences in counter-flow configuration, modelpredicted response due to variations in current density, fuel utilization and level of pre-reforming are compared. The differences between the model predictions are plotted in Figure 14 for operation at 3000 and $5000 \mathrm{~A} \mathrm{~m}^{-2}$ versus percent pre-reforming. It is evident from the plots that the fuel utilization has only a small impact on the modeling differences, where the current density and pre-reforming have larger effects. Increasing the fuel utilization in this region causes increased differences in the tem- 
perature gradient predictions and reduced differences in the peak PEN temperature predictions. If the current density is reduced differences in the peak and maximum PEN temperature differences are reduced, although the differences are still significant. As the level of pre-reforming is reduced, modeling differences cease to exist except for small differences in maximum temperature difference (2-3K) and temperature gradient $(0.2 \mathrm{~K} / \mathrm{mm})$, which can be attributed to the differences in the porous media mass transport models.

The primary conclusion from this study is that if significant reforming is occurring in a counter-flow cell, capturing the effects of coupled mass transport, heterogeneous chemistry and electrochemistry become important. As pre-reforming is increased capturing these effects becomes less important, however, only above $90 \%$ pre-reforming do these effects become negligible. A 'quasi' 2-D model is recommended for a counterflow channel-level model with internal reforming where the PEN temperature profile and gradient are of interest.

\section{Conclusion}

Two sets of dynamic modeling equations for the simulation of SOFCs were developed. The modeling methodologies differed by the representation of the internal reforming reactions and mass transport model. The 1-D model assumed the reforming reactions to occur on the external anode surface and the mass transport to occur as an equimolar counter diffusion process at constant pressure. The 'quasi' 2-D model resolved species concentration profiles throughout the anode depth capturing the coupled effects of internal reforming, mass transport, and electrochemistry.

The electrochemical submodel was calibrated against button cell data where previously determined modeling parameters were found to be in good agreement. The model was then verified against data from a similar cell running on humidified methane. The 'quasi' 2-D model was shown to be in better agreement with the experimental data for 
the cell operating on humidified methane.

Channel-level modeling comparisons displayed the effect of the modeling methodology on the predicted steady-state temperature and current density profiles. Modeling differences were only observed to occur for counter-flow configuration cell with significant levels of internal reforming at high current densities. However, the electrochemical performance of the channel-level model was not significantly changed with modeling methodology. Thus, if accurately resolving the temperature and current density distribution is of importance a 'quasi' 2-D model should be selected. In addition the 'quasi' 2-D model allows for the study of variation in the anode parameters (porosity, tortuosity, ...) directly capturing the effects on fuel reforming and electrochemical performance.

\section{Acknowledgments}

The authors thank the John Poate Fellowship and the National Science Foundation for partial support of this research effort under award \#CNS-0931748.

\section{Nomenclature}

$A_{o} \quad$ Pre-exponential factor (varies)

A Cross sectional area $\left(\mathrm{m}^{2}\right)$

$A R \quad$ Air ratio

Ar Aspect ratio of the fuel or air channel

$B_{\mathrm{g}} \quad$ Permeability of porous media $\left(\mathrm{m}^{2}\right)$

C Molar concentration $\left(\mathrm{mol} \mathrm{m}^{-3}\right)$

$c \quad$ Specific heat of the solid $\left(\mathrm{J} \mathrm{kg}^{-1} \mathrm{~K}^{-1}\right)$

$\mathscr{D} \quad$ Diffusion coefficient $\left(\mathrm{m}^{2} \mathrm{~s}^{-1}\right)$

$D_{c} \quad$ Channel hydraulic diameter (m)

$d_{\mathrm{p}} \quad$ Particle diameter (m) 


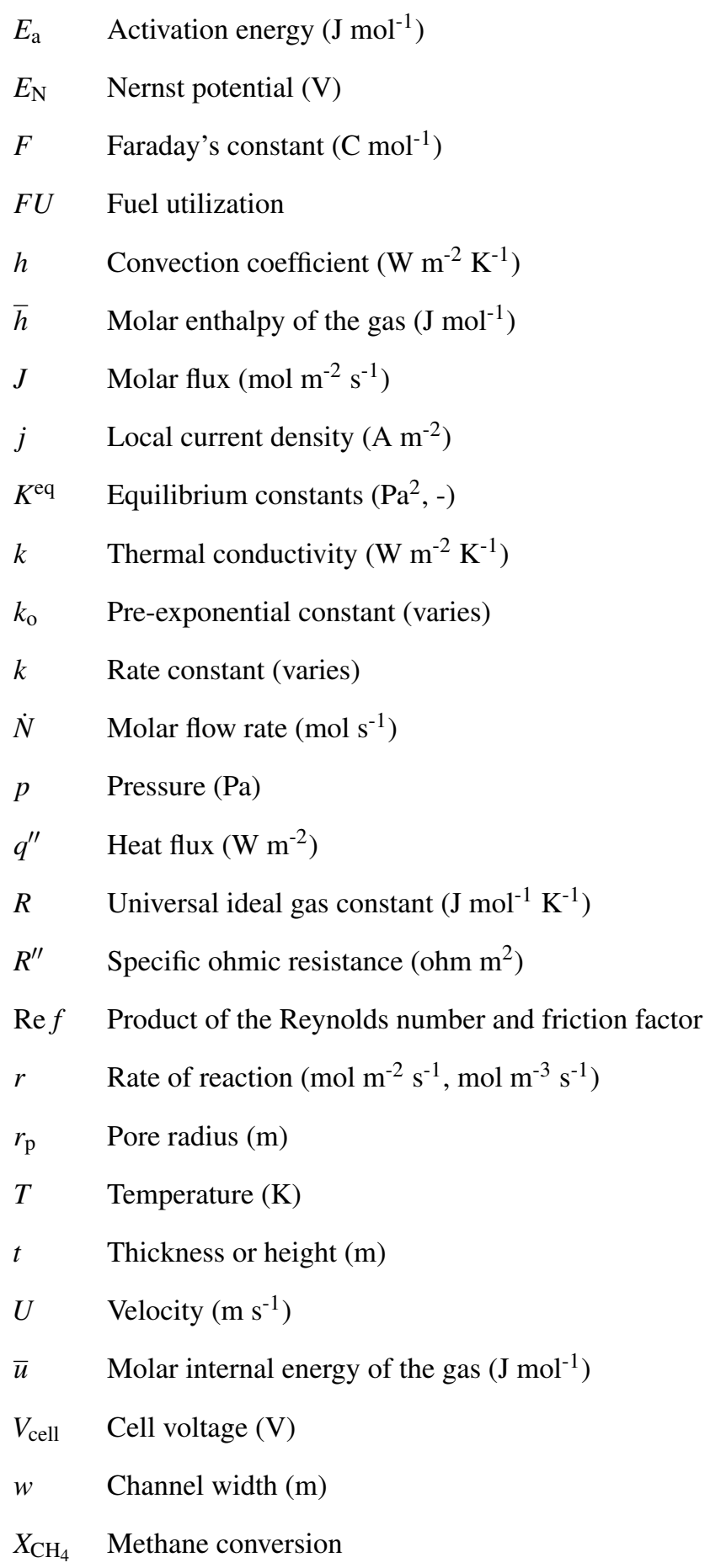




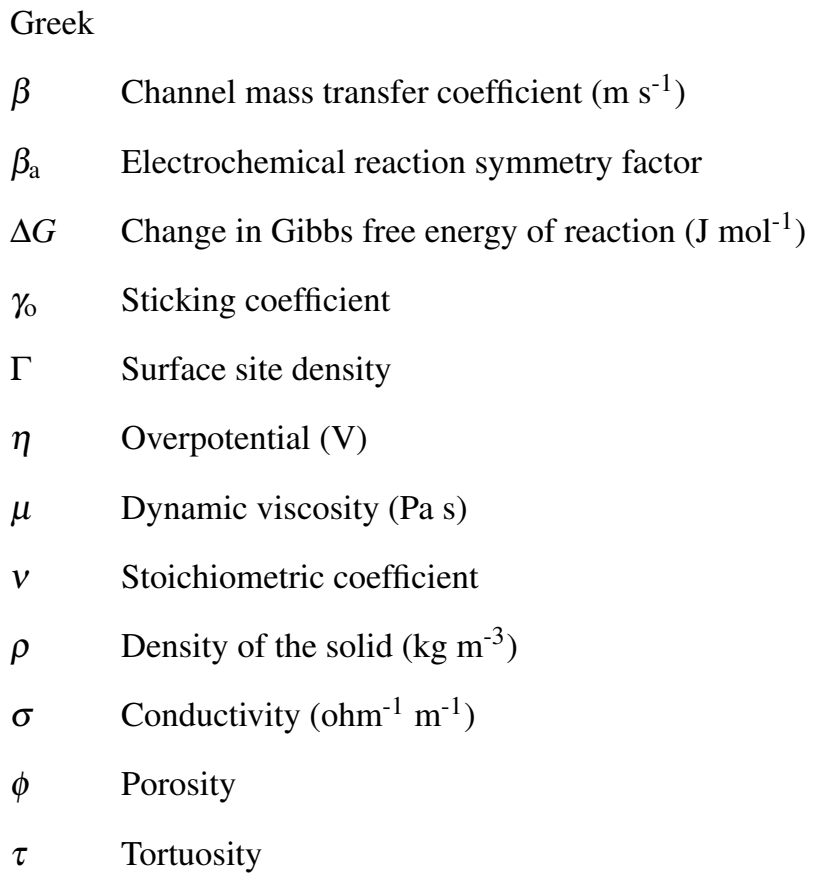

\section{Subscripts}

sa Air species

sf Fuel species

ox Electrochemical oxidation

sr Steam reforming reaction

wgs Water-gas shift reaction

f Fuel

a Air

pen PEN solid

int Interconnect solid

$k \quad$ Reaction index 


$\begin{array}{ll}\text { s } & \text { Surface } \\ \text { o } & \text { Ambient or refference conditions } \\ \text { TPB } & \text { Tripple phase boundary } \\ \text { act } & \text { Activation } \\ \text { ohm } & \text { Ohmic } \\ \text { Kn } & \text { Knudsen } \\ \text { elec } & \text { Electrolyte } \\ \text { dif } & \text { Diffusion } \\ & \\ \text { Superscripts } \\ \text { eff } & \text { Effective } \\ \text { ref } & \text { Reference }\end{array}$

\section{References}

[1] gPROMS modelbuilder 3.6.0, 2012.

[2] E. Achenbach. Three-dimensional and time-dependent simulation of a planar solid oxide fuel cell stack. Journal of Power Sources, 49:333-348, 1994.

[3] E. Achenbach and E. Riensche. Methane/steam reforming kinetics for solid oxide fuel cells. Journal of Power Sources, 52(2):283-288, 1994.

[4] P. Aguiar, C.S. Adjiman, and N.P. Brandon. Anode-supported intermediate temperature direct internal reforming solid oxide fuel cell. I: model-based steadystate performance. Journal of Power Sources, 138:120-136, 2004.

[5] P. Aguiar, C.S. Adjiman, and N.P. Brandon. Anode-supported intermediate- 
temperature direct internal reforming solid oxide fuel cell II. model-based dynamic performance and control. Journal of Power Sources, 147:136-147, 2005.

[6] Khaliq Ahmed and Karl Foger. Kinetics of internal steam reforming of methane on Ni/YSZ-based anodes for solid oxide fuel cells. Catalysis Today, 63:479-487, 2000.

[7] Martin Andersson, Jinliang Yuan, and Bengt Sundan. Review on modeling development for multiscale chemical reactions coupled transport phenomena in solid oxide fuel cells. Applied Energy, 87(5):1461-1476, 2010.

[8] Y. Mollayi Barzi, M. Ghassemi, and M.H. Hamedi. A 2D transient numerical model combining heat/mass transport effects in a tubular solid oxide fuel cell. Journal of Power Sources, 192(1):200-207, 2009.

[9] Simeon Bebelis, Andonis Zeritis, Constantina Tiropani, and Stylianos G. Neophytides. Intrinsic kinetics of the internal steam reforming of $\mathrm{CH} 4$ over a $\mathrm{Ni}$ YSZ cermet catalyst electrode. Industrial \& Engineering Chemistry Research, 39(12):4920-4927, 2000.

[10] M. Boder and R. Dittmeyer. Catalytic modification of conventional SOFC anodes with a view to reducing their activity for direct internal reforming of natural gas. Journal of Power Sources, 155(1):13-22, 2006.

[11] A. Chaisantikulwat, C. Diaz-Goano, and E.S. Meadows. Dynamic modelling and control of planar anode-supported solid oxide fuel cell. Computers \& Chemical Engineering, 32(10):2365-2381, 2008.

[12] Andrew M. Colclasure, Borhan M. Sanandaji, Tyrone L. Vincent, and Robert J. Kee. Modeling and control of tubular solid-oxide fuel cell systems. i: Physical models and linear model reduction. Journal of Power Sources, 196(1):196-207, 2011. 
[13] Steven C. DeCaluwe, Huayang Zhu, Robert J. Kee, and Gregory S. Jackson. Importance of anode microstructure in modeling solid oxide fuel cells. Journal of The Electrochemical Society, 155(6):B538-B546, 2008.

[14] A.L Dicks, K.D Pointon, and A Siddle. Intrinsic reaction kinetics of methane steam reforming on a nickel/zirconia anode. Journal of Power Sources, 86:523$530,2000$.

[15] I. Drescher, W. Lehnert, and J. Meusinger. Structural properties of SOFC anodes and reactivity. Electrochimica Acta, 43:3059-3068, 1998.

[16] Norman Epstein. On tortuosity and the tortuosity factor in flow and diffusion through porous media. Chemical Engineering Science, 44(3):777-779, 1989.

[17] Graham M. Goldin, Huayang Zhu, Robert J. Kee, David Bierschenk, and Scott A. Barnett. Multidimensional flow, thermal, and chemical behavior in solid-oxide fuel cell button cells. Journal of Power Sources, 187(1):123-135, 2009.

[18] David G. Goodwin, Huayang Zhu, Andrew M. Colclasure, and Robert J. Kee. Modeling electrochemical oxidation of hydrogen on Ni-YSZ pattern anodes. Journal of The Electrochemical Society, 156(9):B1004-B1021, 2009.

[19] Ethan S. Hecht, Gaurav K. Gupta, Huayang Zhu, Anthony M. Dean, Robert J. Kee, Luba Maier, and Olaf Deutschmann. Methane reforming kinetics within a Ni-YSZ SOFC anode support. Applied Catalysis A: General, 295(1):40-51, 2005.

[20] P. Iora, P. Aguiar, C.S. Adjiman, and N.P. Brandon. Comparison of two IT DIRSOFC models: Impact of variable thermodynamic, physical, and flow properties. steady-state and dynamic analysis. Chemical Engineering Science, 60(11):2963$2975,2005$. 
[21] Vinod M. Janardhanan and Olaf Deutschmann. CFD analysis of a solid oxide fuel cell with internal reforming: Coupled interactions of transport, heterogeneous catalysis and electrochemical processes. Journal of Power Sources, 162(2):11921202, 2006.

[22] Vinod M. Janardhanan, Vincent Heuveline, and Olaf Deutschmann. Performance analysis of a SOFC under direct internal reforming conditions. Journal of Power Sources, 172(1):296-307, 2007.

[23] Yi Jiang and Anil V. Virkar. Fuel composition and diluent effect on gas transport and performance of anode-supported SOFCs. Journal of The Electrochemical Society, 150(7):A942-A951, 2003.

[24] P. Kazempoor and R.J. Braun. Model validation and performance analysis of regenerative solid oxide cells: Electrolytic operation. International Journal of Hydrogen Energy, 39(6):2669 - 2684, 2014.

[25] P. Kazempoor, V. Dorer, and F. Ommi. Modelling and performance evaluation of solid oxide fuel cell for building integrated co- and polygeneration. Fuel Cells, 10(6):1074-1094, 2010.

[26] Pejman Kazempoor, Fathollah Ommi, and Viktor Dorer. Response of a planar solid oxide fuel cell to step load and inlet flow temperature changes. Journal of Power Sources, 196(21):8948-8954, 2011.

[27] Robert J. Kee, Pavan Korada, Kevin Walters, and Mark Pavol. A generalized model of the flow distribution in channel networks of planar fuel cells. Journal of Power Sources, 109(1):148-159, 2002.

[28] Robert J. Kee, Huayang Zhu, Robert J. Braun, and Tyrone L. Vincent. Advances in Chemical Engineering: Fuel Cell Engineering, chapter Modeling the Steady- 
State and Dynamic Catacteristics of Solid-Oxide Fuel Cells, pages 331-381. Elsevier, 2012.

[29] David L. King, James J. Strohm, Xianqin Wang, Hyun-Seog Roh, Chongmin Wang, Ya-Heui Chin, Yong Wang, Yuanbo Lin, Robert Rozmiarek, and Prabhakar Singh. Effect of nickel microstructure on methane steam-reforming activity of $\mathrm{Ni}$ YSZ cermet anode catalyst. Journal of Catalysis, 258(2):356-365, 2008.

[30] Alexander Kromp, André Leonide, Henrik Timmermann, André Weber, and Ellen Ivers-Tiffée. Internal reforming kinetics in SOFC-anodes. ECS Transactions, 28(11):205-215, 2010.

[31] J. Lapujoulade and K. S. Neil. Chemisorption of hydrogen on the (111) plane of nickel. The Journal of Chemical Physics, 57(8):3535-3545, 1972.

[32] Yuanbo Lin, Zhongliang Zhan, Jiang Liu, and Scott A. Barnett. Direct operation of solid oxide fuel cells with methane fuel. Solid State Ionics, 176:1827-1835, 2005.

[33] E. A. Mason and A. P. Malinauskas. Gas Transport in Porous Media: The DustyGas Model. Elsevier, 1983.

[34] Yoshio Matsuzaki and Isamu Yasuda. Relationship between the steady-state polarization of the sofc air electrode and its complex impedance measured at the equilibrium potential. Solid State Ionics, 126:307-313, 1999.

[35] Vikram Menon, Vinod M. Janardhanan, Steffen Tischer, and Olaf Deutschmann. A novel approach to model the transient behavior of solid-oxide fuel cell stacks. Journal of Power Sources, 214(0):227 - 238, 2012.

[36] Junichiro Mizusaki, Hiroaki Tagawa, Takatoshi Saito, Tamaki Yamamura, Kouji Kamitani, Katsuhiko Hirano, Shaw Ehara, Toshinori Takagi, Tomoji Hikita, Masamichi Ippommatsu, Shigeto Nakagawa, and Keiichi Hashimoto. Kinetic 
studies of the reaction at the nickel pattern electrode on YSZ in $\mathrm{H} 2-\mathrm{H} 2 \mathrm{O}$ atmospheres. Solid State Ionics, 70/71(0):52-58, 1994.

[37] D. Mogensen, J.-D. Grunwaldt, P.V. Hendriksen, K. Dam-Johansen, and J.U. Nielsen. Internal steam reforming in solid oxide fuel cells: Status and opportunities of kinetic studies and their impact on modelling. Journal of Power Sources, 196(1):25-38, 2011.

[38] Connor J. Moyer, Neal P. Sullivan, Huayang Zhu, and Robert J. Kee. Polarization characteristics and chemistry in reversible tubular solid-oxide cells operating on mixtures of $\mathrm{H} 2, \mathrm{CO}, \mathrm{H} 2 \mathrm{O}$, and $\mathrm{CO}$. Journal of The Electrochemical Society, 158(2):B117-B131, 2011.

[39] Fabian Mueller, Jacob Brouwer, Faryar Jabbari, and Scott Samuelsen. Dynamic simulation of an integrated solid oxide fuel cell system including current-based fuel flow control. Journal of Fuel Cell Science and Technology, 3:144-154, 2006.

[40] A. Nakajo, F. Mueller, D. McLarty, J. Brouwer, J. Van herle, and D. Favrat. The effects of dynamic dispatch on the degradation and lifetime of solid oxide fuel cell systems. Journal of The Electrochemical Society, 158(11):B1329-B1340, 2011.

[41] Arata Nakajo, Pietro Tanasini, Stefan Diethelm, Jan Van herle, and Daniel Favrat. Electrochemical model of solid oxide fuel cell for simulation at the stack scale II: Implementation of degradation processes. Journal of The Electrochemical Society, 158(9):B1102-B1118, 2011.

[42] Arata Nakajo, Zacharie Wuillemin, Jan Van herle, and Daniel Favrat. Simulation of thermal stresses in anode-supported solid oxide fuel cell stacks. part I: Probability of failure of the cells. Journal of Power Sources, 193(1):203 - 215, 2009. 
[43] Kimihiro Nanaeda, Fabian Mueller, Jacob Brouwer, and Scott Samuelsen. Dynamic modeling and evaluation of solid oxide fuel cell - combined heat and power system operating strategies. Journal of Power Sources, 195(10):3176$3185,2010$.

[44] Meng Ni, Dennis Y.C. Leung, and Michael K.H. Leung. Importance of pressure gradient in solid oxide fuel cell electrodes for modeling study. Journal of Power Sources, 183(2):668-673, 2008.

[45] R. Peters, R. Dahl, U. Klüttgen, C. Palm, and D. Stolten. Internal reforming of methane in solid oxide fuel cell systems. Journal of Power Sources, 106:238-244, 2002.

[46] Bruce E. Poling, John M. Prausnitz, and John P. O’Connell. Properties of Gases and Liquids. McGRAW-HILL, 2001.

[47] Kristopher A. Pruitt, Robert J. Braun, and Alexandra M. Newman. Evaluating shortfalls in mixed-integer programming approaches for the optimal design and dispatch of distributed generation systems. Applied Energy, 102(0):386-398, 2013.

[48] Yutong Qi, Biao Huang, and Karl T. Chuang. Dynamic modeling of solid oxide fuel cell: The effect of diffusion and inherent impedance. Journal of Power Sources, 150(0):32-47, 2005.

[49] Yutong Qi, Biao Huang, and Jingli Luo. Dynamic modeling of a finite volume of solid oxide fuel cell: The effect of transport dynamics. Chemical Engineering Science, 61(18):6057-6076, 2006.

[50] Borhan M. Sanandaji, Tyrone L. Vincent, Andrew M. Colclasure, and Robert J. Kee. Modeling and control of tubular solid-oxide fuel cell systems: Ii. nonlin- 
ear model reduction and model predictive control. Journal of Power Sources, 196(1):208-217, 2011.

[51] Andrew T. Schmidt. Dynamic modeling of solid oxide fuel cell systems for commercial building applications. Master's thesis, Colorado School of Mines, 2011.

[52] R. K. Shah and A. L. London. Advances in Heat Transfer: Laminar Flow and Forced Convection in Ducts. Elsevier Science and Technology, 1979.

[53] R. Suwanwarangkul, E. Croiset, M.W. Fowler, P.L. Douglas, E. Entchev, and M.A. Douglas. Performance comparison of fick's, dusty-gas and stefan-maxwell models to predict the concentration overpotential of a sofc anode. Journal of Power Sources, 122(1):9-18, 2003.

[54] H. Timmermann, W. Sawady, R. Reimert, and E. Ivers-Tiffée. Kinetics of (reversible) internal reforming of methane in solid oxide fuel cells under stationary and APU conditions. Journal of Power Sources, 195(1):214-222, 2010.

[55] Anil V. Virkar. A model for solid oxide fuel cell (sofc) stack degradation. Journal of Power Sources, 172(2):713-724, 2007.

[56] Yasemin Vural, Lin Ma, Derek B. Ingham, and Mohamed Pourkashanian. Comparison of the multicomponent mass transfer models for the prediction of the concentration overpotential for solid oxide fuel cell anodes. Journal of Power Sources, 195(15):4893-4904, 2010.

[57] Shuping Wang, William M. Worek, and W.J. Minkowycz. Performance comparison of the mass transfer models with internal reforming for solid oxide fuel cell anodes. International Journal of Heat and Mass Transfer, 55:3933-3945, 2012.

[58] Junmei Wei and Enrique Iglesia. Isotopic and kinetic assessment of the mechanism of reactions of $\mathrm{CH} 4$ with $\mathrm{CO} 2$ or $\mathrm{H} 2 \mathrm{O}$ to form synthesis gas and carbon on nickel catalysts. Journal of Catalysis, 224(2):370-383, 2004. 
[59] Jianguo $\mathrm{Xu}$ and Gilbert F. Froment. Methane steam reforming: II. diffusional limitations and reactor simulation. AIChE Journal, 35(1):97-103, 1989.

[60] Jianguo Xu and Gilbert F. Froment. Methane steam reforming, methanation and water-gas shift: I. intrinsic kinetics. AIChE Journal, 35(1):88-96, 1989.

[61] Jinliang Yuan and Bengt Sundan. Analysis of chemically reacting transport phenomena in an anode duct of intermediate temperature SOFCs. Journal of Fuel Cell Science and Technology, 3:89-98, 2006.

[62] Huayang Zhu and Robert J. Kee. Modeling distributed charge-transfer processes in SOFC membrane electrode assemblies. Journal of The Electrochemical Society, 155(7):B715-B729, 2008.

[63] Huayang Zhu, Robert J. Kee, Vinod M. Janardhanan, Olaf Deutschmann, and David G. Goodwin. Modeling elementary heterogeneous chemistry and electrochemistry in solid-oxide fuel cells. Journal of The Electrochemical Society, 152(12):A2427-A2440, 2005. 


\section{List of Fgiures}

1. Planar SOFC illustration [28]

2. Graphical representation of the 1-D interface charge transfer channel-level model

3. Graphical representation of the 'quasi' 2-D interface charge transfer channellevel model

4. $\mathrm{H}_{2}-\mathrm{H}_{2} \mathrm{O}$ button cell model verification using the data of Lin et al. [32] $\left(97 \% \mathrm{H}_{2}+3 \% \mathrm{H}_{2} \mathrm{O}\right.$, 30 sccm fuel, ambient air)

5. $\mathrm{CH}_{4}-\mathrm{H}_{2} \mathrm{O}$ button cell model verification using the data of Lin et al. [32] $\left(97 \% \mathrm{CH}_{4}+3 \% \mathrm{H}_{2} \mathrm{O}\right.$, $30 \mathrm{sccm}$ fuel, ambient air)

6. Anode species profiles for operating points A and B (A: $97 \% \mathrm{H}_{2}-\mathrm{H}_{2} \mathrm{O}, 10000$ $\left.\mathrm{A} \mathrm{m}^{-2}, 800^{\circ} \mathrm{C} ; \mathrm{B}: 97 \% \mathrm{CH}_{4}-\mathrm{H}_{2} \mathrm{O}, 10000 \mathrm{~A} \mathrm{~m}^{-2}, 800^{\circ} \mathrm{C}\right)$

7. Channel-level model verification using the data of Kromp et al. [30]

8. Channel-level model methane conversion comparison

9. Channel-level model verification displaying the effect of constant fuel flow rate

10. Channel-level model verification displaying the effect of constant nominal cell temperature

11. Co-flow modeling comparison operating under low levels (10\%) of fuel prereforming

12. Counter-flow modeling comparison operating under low levels (10\%) of fuel pre-reforming

13. Counter-flow modeling comparison operating under high levels $(99 \%)$ of fuel pre-reforming

14. Counter-flow channel-level modeling comparisons of maximum PEN temperature difference, peak PEN temperature difference, and maximum PEN temperature gradient difference at $3000 \mathrm{~A} \mathrm{~m}^{-2}$ and $5000 \mathrm{~A} \mathrm{~m}^{-2}(65,75$ and $85 \%$ fuel utilization, 8.0 air ratio) 


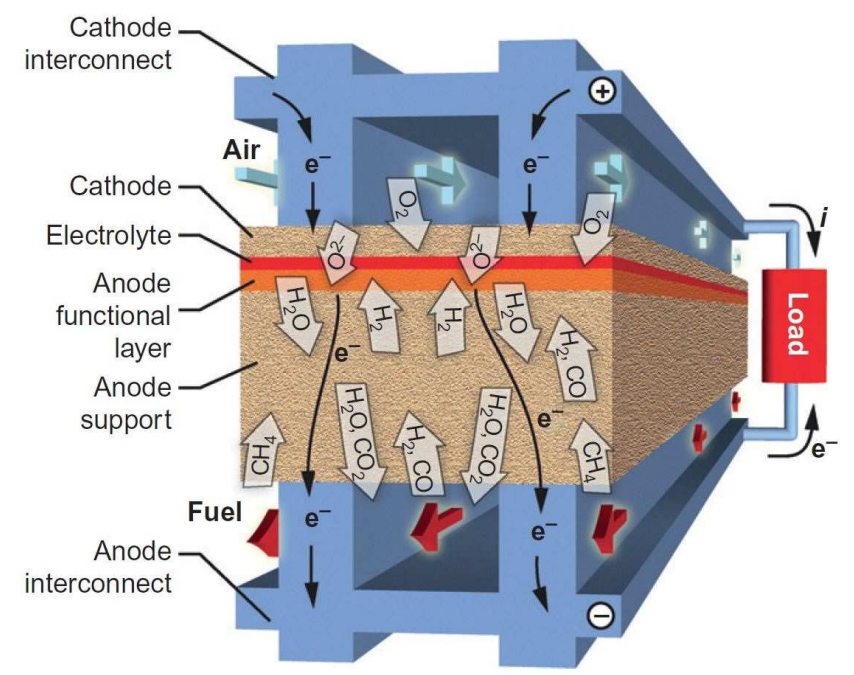

Figure 1: Planar SOFC illustration [28] 


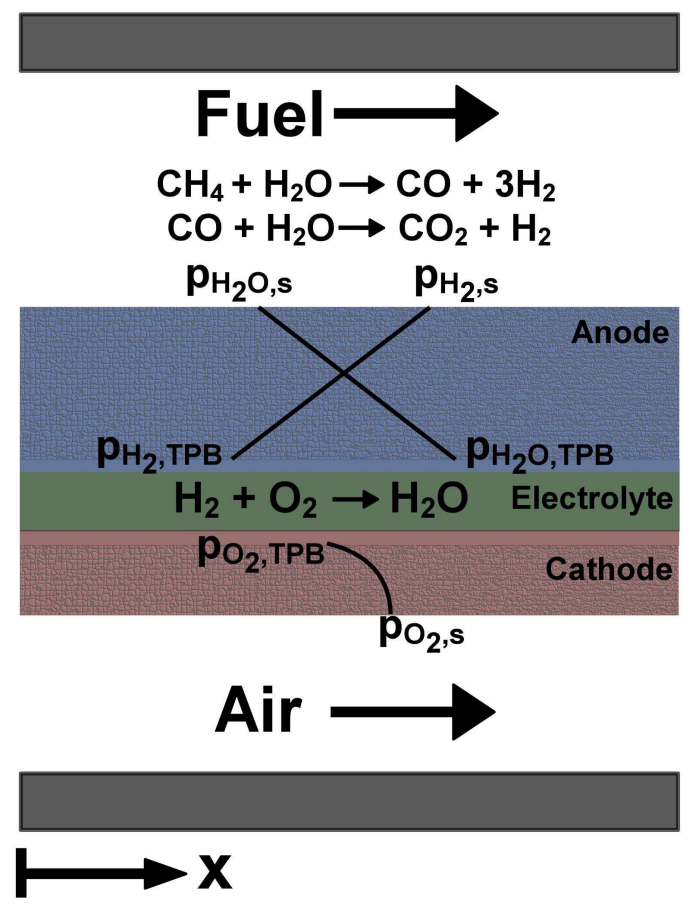

Figure 2: Graphical representation of the 1-D interface charge transfer channel-level model 


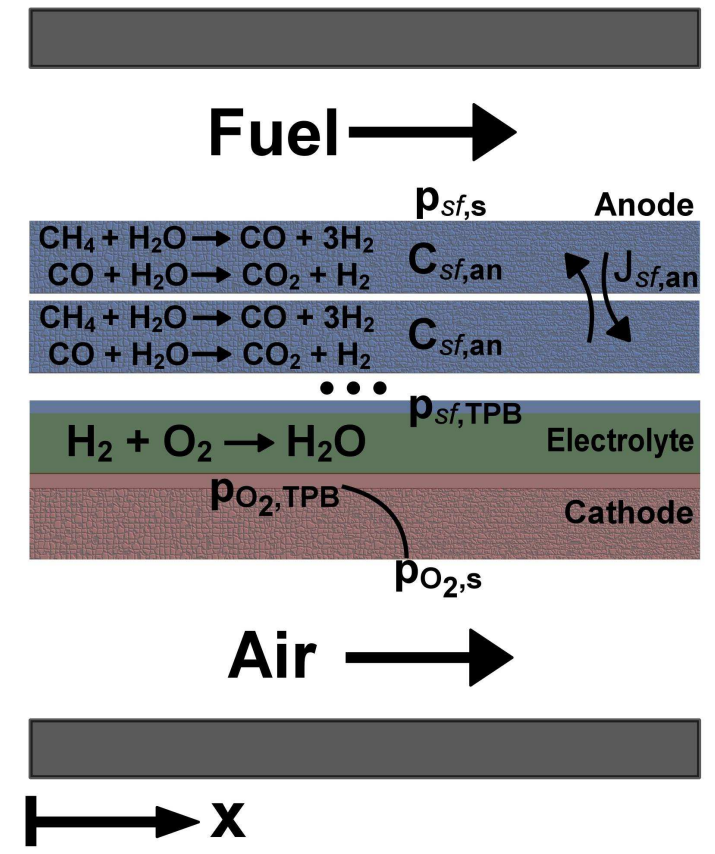

Figure 3: Graphical representation of the 'quasi' 2-D interface charge transfer channel-level model 


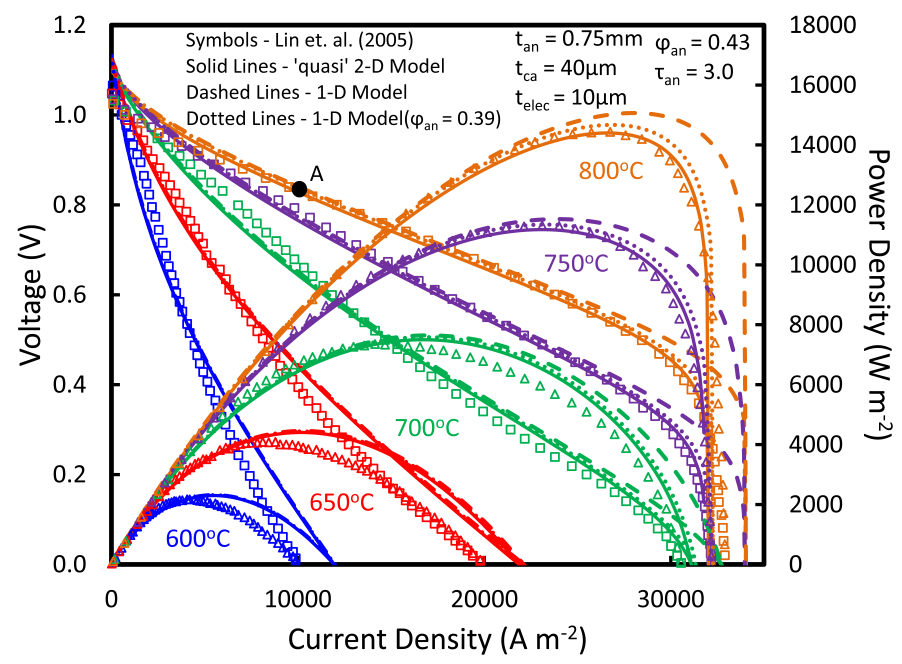

Figure 4: $\mathrm{H}_{2}-\mathrm{H}_{2} \mathrm{O}$ button cell model verification using the data of Lin et al. [32] $\left(97 \% \mathrm{H}_{2}+3 \% \mathrm{H}_{2} \mathrm{O}, 30 \mathrm{sccm}\right.$ fuel, ambient air) 


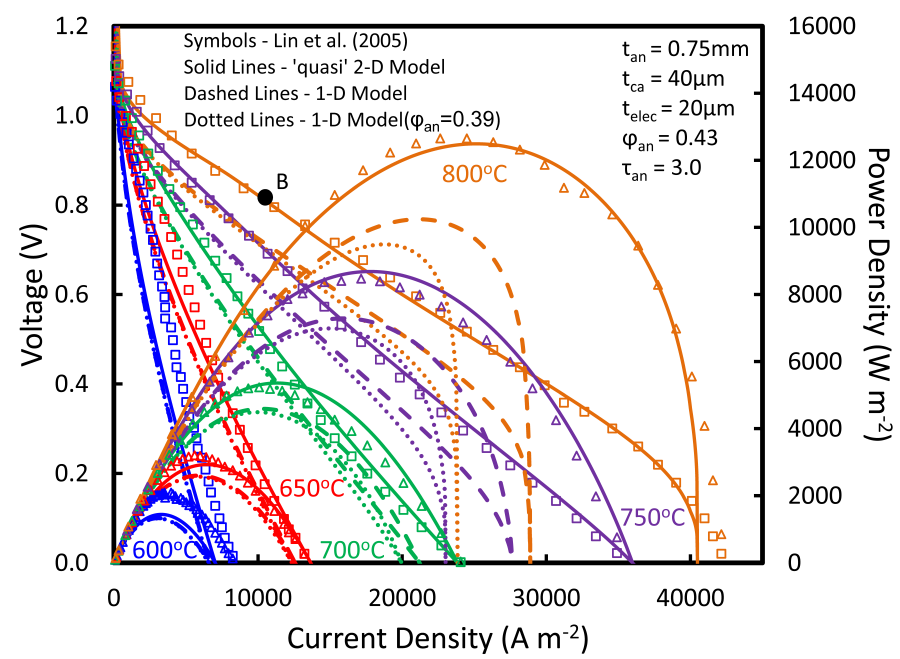

Figure 5: $\mathrm{CH}_{4}-\mathrm{H}_{2} \mathrm{O}$ button cell model verification using the data of Lin et al. [32] $\left(97 \% \mathrm{CH}_{4}+3 \% \mathrm{H}_{2} \mathrm{O}, 30\right.$ sccm fuel, ambient air) 


\section{Operating Point A Operating Point B}

Species Partial Pressure (Pa)

Species Partial Pressure ( $\mathrm{Pa}$ )

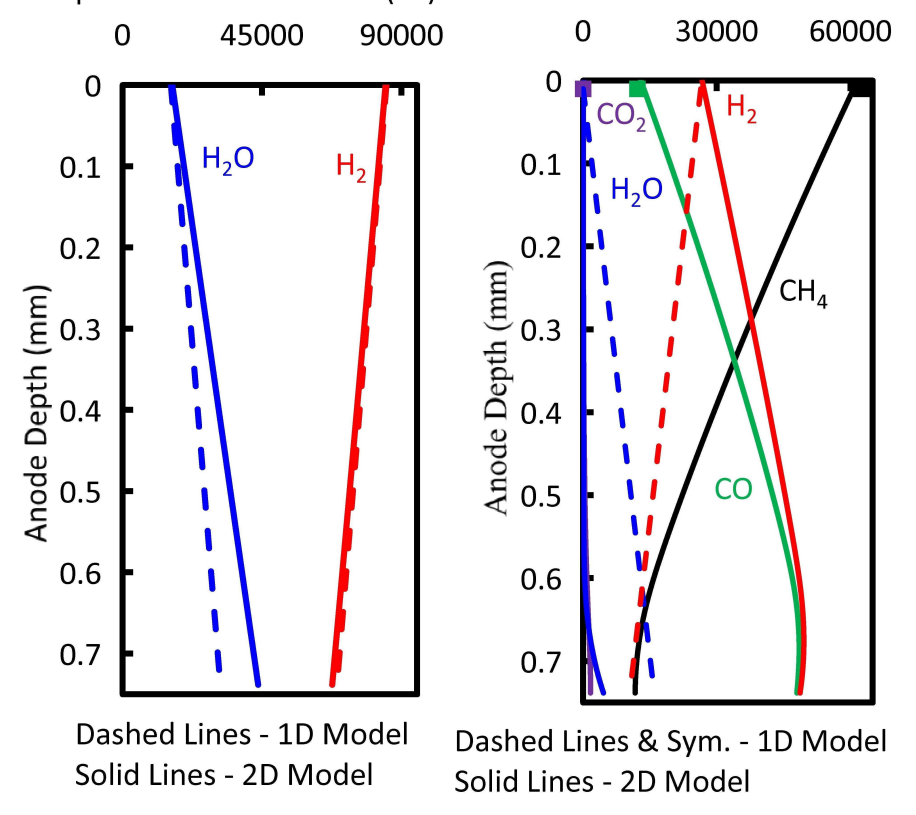

Figure 6: Anode species profiles for operating points A and B $\left(\mathrm{A}: 97 \% \mathrm{H}_{2}-\mathrm{H}_{2} \mathrm{O}, 10000 \mathrm{~A} \mathrm{~m}^{-2}, 800^{\circ} \mathrm{C}\right.$; B: $97 \% \mathrm{CH}_{4}-\mathrm{H}_{2} \mathrm{O}, 10000 \mathrm{~A} \mathrm{~m}^{-2}, 800^{\circ} \mathrm{C}$ ) 


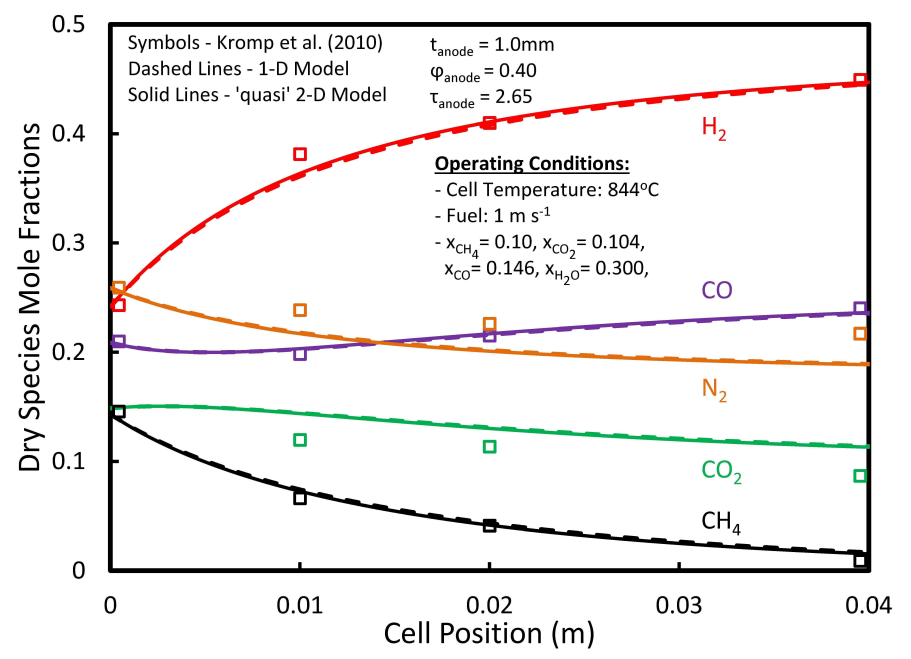

Figure 7: Channel-level model verification using the data of Kromp et al. [30] 


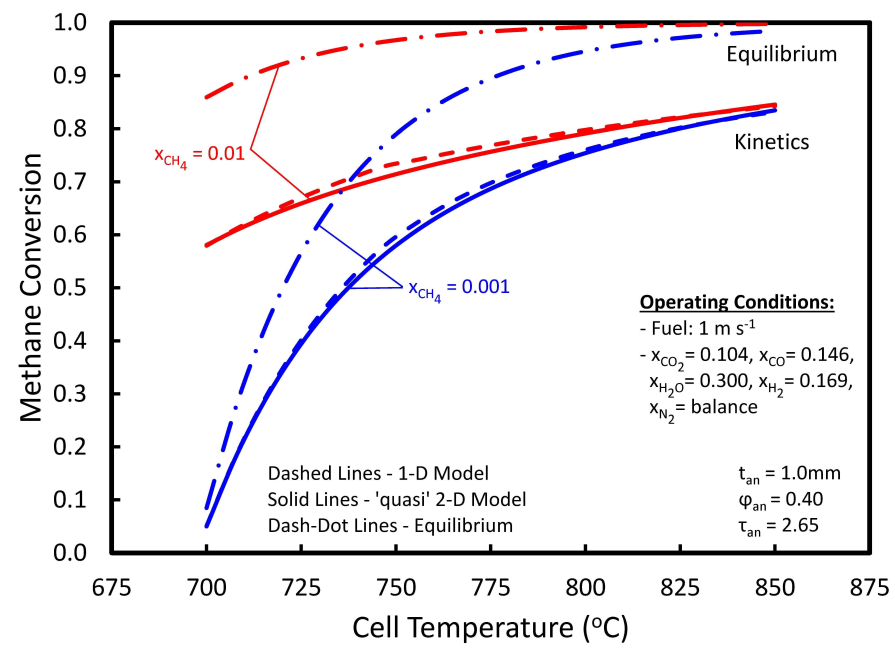

Figure 8: Channel-level model methane conversion comparison 


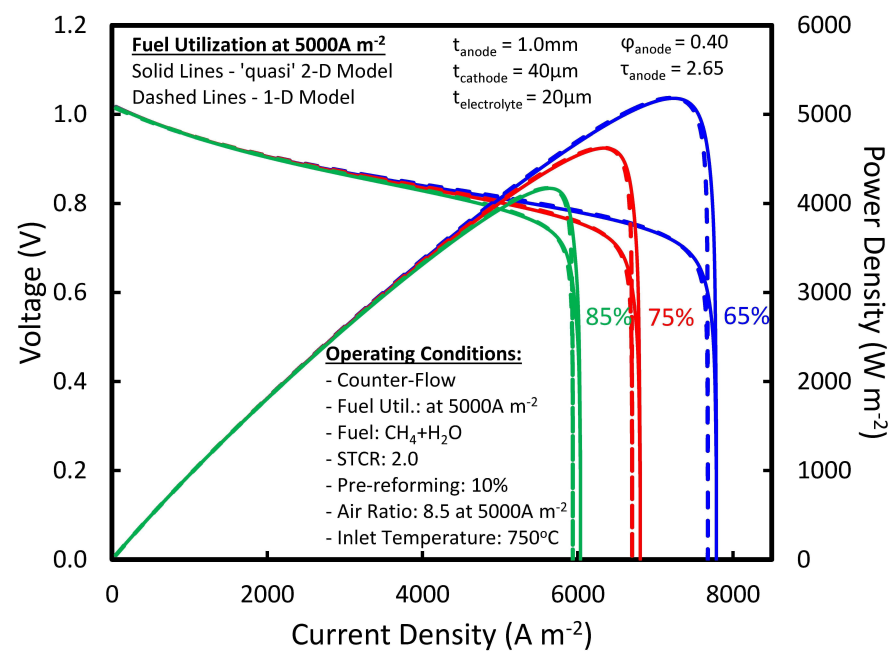

Figure 9: Channel-level model verification displaying the effect of constant fuel flow rate 


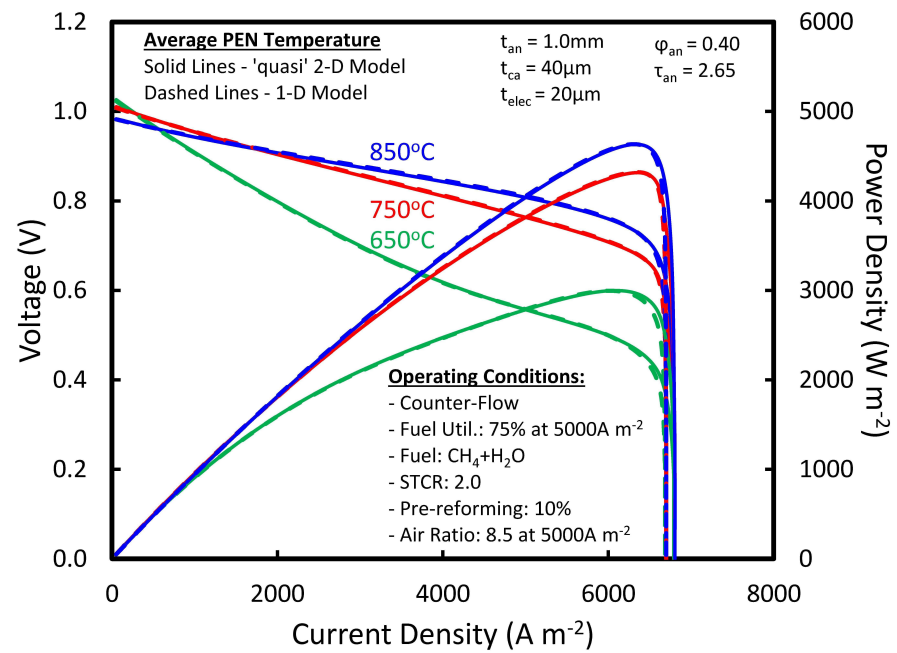

Figure 10: Channel-level model verification displaying the effect of constant nominal cell temperature 


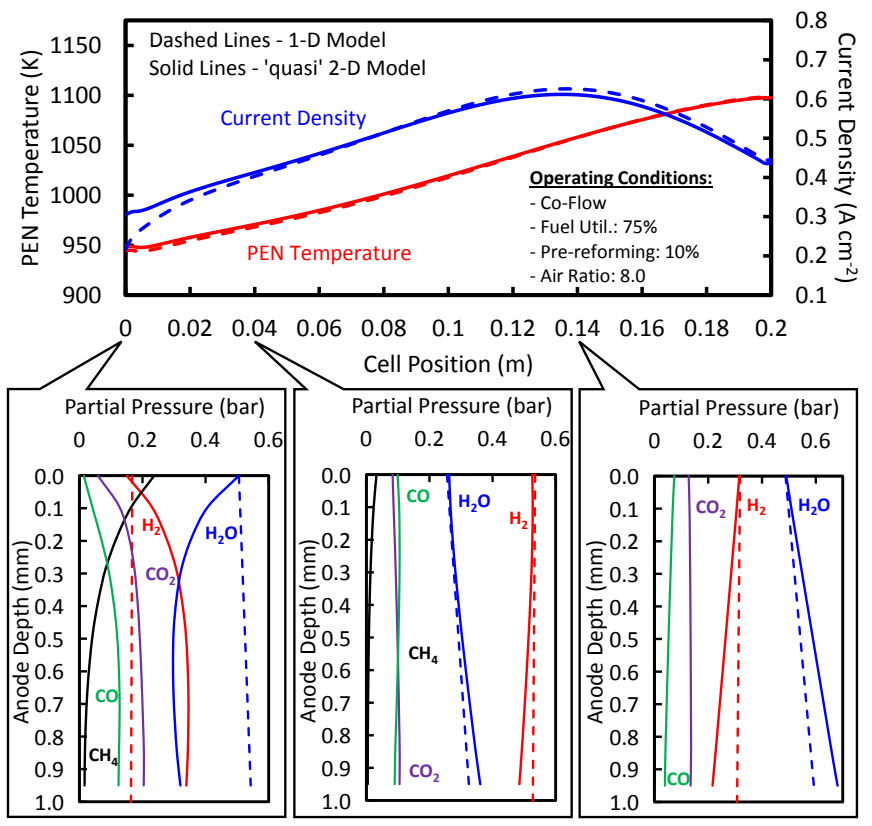

Figure 11: Co-flow modeling comparison operating under low levels (10\%) of fuel pre-reforming 


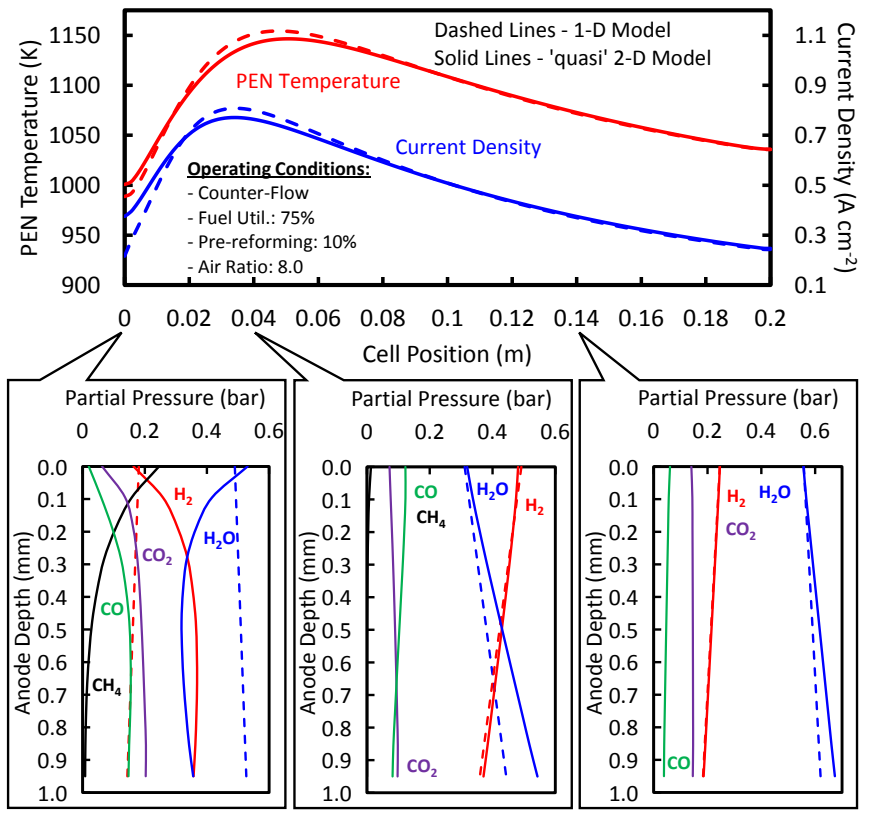

Figure 12: Counter-flow modeling comparison operating under low levels (10\%) of fuel pre-reforming 


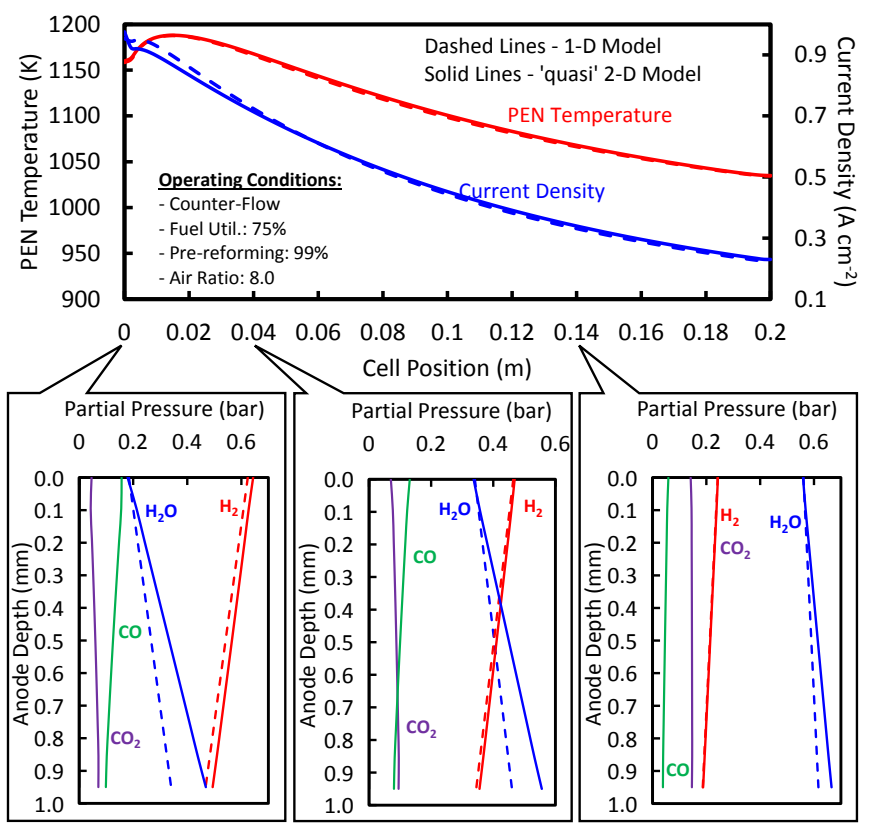

Figure 13: Counter-flow modeling comparison operating under high levels (99\%) of fuel pre-reforming 

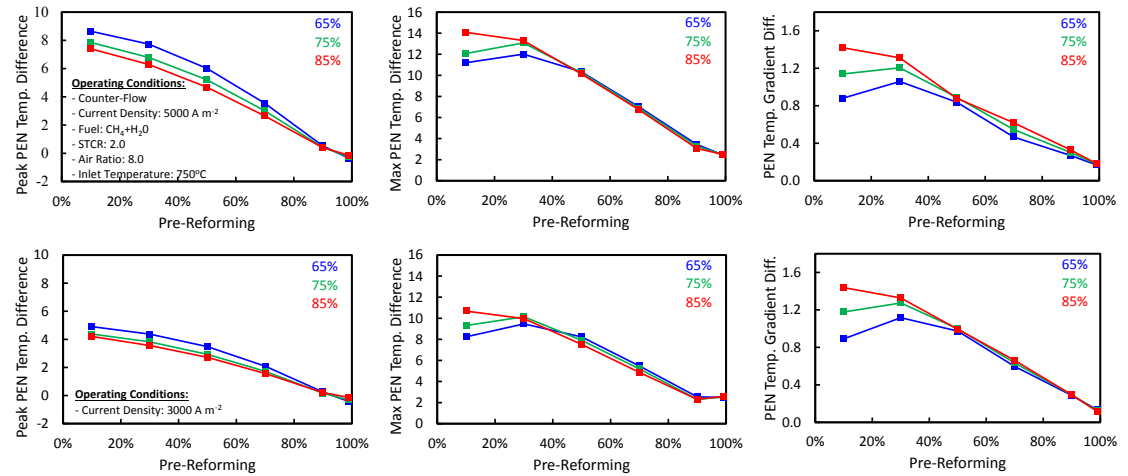

Figure 14: Counter-flow channel-level modeling comparisons of maximum PEN temperature difference, peak PEN temperature difference, and maximum PEN temperature gradient difference at $3000 \mathrm{~A} \mathrm{~m}^{-2}$ and $5000 \mathrm{~A} \mathrm{~m}^{-2}(65,75$ and $85 \%$ fuel utilization, 8.0 air ratio) 


\section{List of Tables}

1. Timmermann et al. [54] rate expression constants

2. 'Quasi' 2-D reforming rate expression constants [30]

3. Electrochemical modeling parameters

4. Channel modeling parameters 
Table 1: Timmermann et al. [54] rate expression constants

\begin{tabular}{lll}
\hline Temperature Range & Pre-exponential $\left(k_{\mathrm{o}, \mathrm{sr}}\right)$ & Activation Energy $\left(E_{\mathrm{a}, \mathrm{sr}}\right)$ \\
\hline $873 \mathrm{~K}<T_{\text {pen }}<1023 \mathrm{~K}$ & $872.4 \mathrm{~mol} \mathrm{~s}^{-1} \mathrm{~m}^{-2} \mathrm{bar}^{-1}$ & $61 \mathrm{~kJ} \mathrm{~mol}^{-1}$ \\
$1023 \mathrm{~K}<T_{\text {pen }}<1123 \mathrm{~K}$ & $22.35 \mathrm{~mol} \mathrm{~s}^{-1} \mathrm{~m}^{-2} \mathrm{bar}^{-1}$ & $30 \mathrm{~kJ} \mathrm{~mol}^{-1}$ \\
\hline
\end{tabular}


Table 2: 'Quasi' 2-D reforming rate expression constants [30]

\begin{tabular}{lll}
\hline Reaction & Pre-exponential Constant $\left(k_{\mathrm{o}, k}\right)$ & Activation Energy $\left(E_{\mathrm{a}, k}\right)$ \\
\hline Steam Reforming $(\mathrm{sr})$ & $30.14 \mathrm{~mol} \mathrm{~s}^{-1} \mathrm{~m}^{-3} \mathrm{~Pa}^{-1}$ & $61000 \mathrm{~kJ} \mathrm{~mol}^{-1}$ \\
\hline
\end{tabular}


Table 3: Electrochemical modeling parameters

\begin{tabular}{lll}
\hline Parameter & Value & Units \\
\hline Anode Exchange Current Density $\left(j_{\mathrm{o}, \text { an }}^{\text {ref }}\right)[21]$ & $2.07 \mathrm{E} 9$ & $\mathrm{~A} \mathrm{~m}^{-2}$ \\
Anode Activation Energy $\left(E_{\mathrm{a}, \text { an }}\right)[21]$ & 87.8 & $\mathrm{~kJ} \mathrm{~mol}^{-1}$ \\
Anode Charge Transfer Coefficient $\left(\beta_{\mathrm{a}, \text { and }}\right)[21]$ & 0.5 & - \\
Cathode Exchange Current Density $\left(j_{\mathrm{o}, \mathrm{ca}}^{\text {ref }}\right)[21]$ & $5.19 \mathrm{E} 8$ & $\mathrm{~A} \mathrm{~m}^{-2}$ \\
Cathode Activation Energy $\left(E_{\mathrm{a}, \mathrm{ca}}\right)[21]$ & 88.6 & $\mathrm{~kJ} \mathrm{~mol}^{-1}$ \\
Cathode Charge Transfer Coefficient $\left(\beta_{\mathrm{a}, \mathrm{ca}}\right)[21]$ & 0.5 & - \\
Hydrogen Desorption Pre-exponential $\left(A_{\mathrm{H}_{2}}\right)[63]$ & $5.59 \mathrm{E} 15$ & $\mathrm{~m} \mathrm{~m} \mathrm{sol}^{-1}$ \\
Hydrogen Desorption Activation Energy $\left(E_{\mathrm{a}, \mathrm{H}}\right)[63]$ & 88.12 & $\mathrm{~kJ} \mathrm{~mol}^{-1}$ \\
Hydrogen Desorption Sticking Coefficient $\left(\gamma_{\mathrm{o}}\right)[63]$ & 0.01 & - \\
Oxygen Desorption Pre-exponential $\left(A_{\mathrm{O}_{2}}\right)[63]$ & $4.9 \mathrm{E} 13$ & $\mathrm{~Pa}^{-}$ \\
Oxygen Desorption Activation Energy $\left(E_{\mathrm{a}, \mathrm{O}_{2}}\right)[63]$ & 200 & $\mathrm{~kJ} \mathrm{~mol}^{-1}$ \\
Anode Electrical Conductivity $\left(\sigma_{\mathrm{an}}\right)[4]$ & $80 \mathrm{E} 3$ & $\mathrm{ohm}^{-1} \mathrm{~m}^{-1}$ \\
Cathode Electrical Conductivity $\left(\sigma_{\mathrm{ca}}\right)[4]$ & $8.4 \mathrm{E} 3$ & $\mathrm{ohm}^{-1} \mathrm{~m}^{-1}$ \\
Electrolyte Ionic Conductivity $\left(\sigma_{\mathrm{elec}}\right)[4]$ & $33.4 \mathrm{E} 3 \exp \left(-10.3 E 3 / T_{\mathrm{pen}}\right)$ & $\mathrm{ohm}^{-1} \mathrm{~m}^{-1}$ \\
\hline
\end{tabular}


Table 4: Channel modeling parameters

\begin{tabular}{lll}
\hline Parameter & Value & Units \\
\hline Channel Width $(w)$ & 20.0 & $\mathrm{~cm}$ \\
Channel Length $(l)$ & 20.0 & $\mathrm{~cm}$ \\
Fuel Channel Height $\left(t_{\mathrm{f}}\right)$ & 1.0 & $\mathrm{~mm}$ \\
Air Channel Height $\left(t_{\mathrm{a}}\right)$ & 1.0 & $\mathrm{~mm}$ \\
Interconnect Thickness $\left(t_{\text {int }}\right)$ & 500 & $\mu \mathrm{m}$ \\
Anode Thickness $\left(t_{\text {an }}\right)$ & 1000 & $\mu \mathrm{m}$ \\
Cathode Thickness $\left(t_{\text {ca }}\right)$ & 40 & $\mu \mathrm{m}$ \\
Electrolyte Thickness $\left(t_{\text {elec }}\right)$ & 20 & $\mu \mathrm{m}$ \\
Anode Porosity $\left(\phi_{\text {an }}\right)$ & 0.40 & - \\
Cathode Porosity $\left(\phi_{\text {ca }}\right)$ & 0.40 & - \\
Anode Tortuosity $\left(\tau_{\text {an }}\right)$ & 2.65 & - \\
Cathode Tortuosity $\left(\tau_{\text {ca }}\right)$ & 2.65 & - \\
PEN Density $\left(\rho_{\text {pen }}\right)[4]$ & 5900 & $\mathrm{~kg} \mathrm{~m}^{-3}$ \\
Interconnect Density $\left(\rho_{\text {int }}\right)[4]$ & 8000 & $\mathrm{~kg} \mathrm{~m}^{-3}$ \\
PEN Heat Capacity $\left(c_{\text {pen }}\right)[4]$ & 0.5 & $\mathrm{~kJ} \mathrm{~kg}^{-1}$ \\
Interconnect Heat Capacity $\left(c_{\text {int }}\right)[4]$ & 0.5 & $\mathrm{~kJ} \mathrm{~kg}^{-1}$ \\
PEN Thermal Conductivity $\left(k_{\text {pen }}\right)[4]$ & $2.0 \mathrm{E}-3$ & $\mathrm{~kW} \mathrm{~m}^{-1} \mathrm{~K}^{-1}$ \\
Int Thermal Conductivity $\left(k_{\text {int }}\right)[4]$ & $25.0 \mathrm{E}-3$ & $\mathrm{~kW} \mathrm{~m}^{-1} \mathrm{~K}^{-1}$ \\
\hline & & \\
\hline
\end{tabular}

